\title{
Resilience, well-being, and organizational outcomes of Croatian, Thai, and US workers during COVID-19
}

\author{
Piyawan Charoensap-Kelly ${ }^{1}$ (D) Pavica Sheldon², Mary Grace Antony ${ }^{3}$ and Laura Provenzani ${ }^{4}$ \\ ${ }^{1}$ Corporate Communication and Public Affairs Division, Southern Methodist University, 3300 Dyer St., ULEE 216, Dallas, \\ TX 75205, USA, ${ }^{2}$ Department of Communication, University of South Alabama, CA 100 University of South Alabama, \\ Mobile, AL, USA, ${ }^{3}$ Edmonds College, 20000 68th Ave W, Lynnwood, WA 98036, USA and ${ }^{4}$ University of Alabama in \\ Huntsville, 320 Sparkman Drive, Huntsville, AL 35805, USA \\ Author for correspondence: Piyawan Charoensap-Kelly, E-mail: pckelly@smu.edu
}

(Received 22 January 2021; revised 25 September 2021; accepted 21 October 2021; first published online 27 October 2021)

\begin{abstract}
Drawing on social cognitive theory (SCT), this study examines the effects of employee resilience, through well-being, on job productivity, and relational satisfaction among extraverted versus introverted workers in Croatia, Thailand, and the United States during the early period of the coronavirus disease 2019 pandemic. Participants included 832 working adults from various industries. Moderated mediation analyses revealed employee resilience positively predicted psychological well-being which, in turn, positively predicted both productivity and relational satisfaction. Regardless of culture, extraverted workers reported less productivity but greater satisfaction with coworkers compared to introverted workers. Also, resilience dampened the negative effects of introversion on relational satisfaction. The findings support the multilevel perspective of resilience and SCT assertion that behavioral outcomes are determined by an interaction between personal and environmental factors and highlight the need to promote employee resilience and well-being during times of crisis. Recommendations on how managers can support employees during this unprecedented global health crisis are provided.
\end{abstract}

Key words: Employee resilience; productivity; relational satisfaction; social cognitive theory; well-being

The world is grappling with the acute respiratory disease (coronavirus disease 2019 [COVID-19]) pandemic caused by the SARS-CoV-2 novel coronavirus that has systematically devastated individual lives, healthcare systems, and global economies. Since its reported origin in Wuhan, China, in December 2019, the number of recorded COVID-19 cases has risen exponentially to encompass almost every single country and continent. At the time of writing (September 2021), the World Health Organization registers over 200 million confirmed cases of COVID-19 and over 4 million deaths. To date, the highest number of confirmed cases has been recorded in the United States, closely followed by India, Brazil, and Russia (World Health Organization, 2021).

In addition to the staggering loss of lives, this pandemic is disrupting organizational practices in unimaginable ways (Stephens et al., 2020). With state-imposed social-distancing guidelines and lockdown measures (Gershman, 2020), businesses have quickly pivoted to teleworking, temporarily or permanently closing, and providing amenities to keep employees healthy, while striving to still meet the needs of consumers and other stakeholders (Kniffin et al., 2021). Employees have been challenged to adapt to these new organizational structures, as they struggle to balance their regular work routine with anxiety about the pandemic, caring for loved ones, and personal health and wellness (Kocjan, Kavčič, \& Avsec, 2021; Xiong et al., 2020). These stressful demands have

\footnotetext{
(C) The Author(s), 2021. Published by Cambridge University Press in association with Australian and New Zealand Academy of Management. This is an Open Access article, distributed under the terms of the Creative Commons Attribution-NonCommercial-ShareAlike licence (https:// creativecommons.org/licenses/by-nc-sa/4.0/), which permits non-commercial re-use, distribution, and reproduction in any medium, provided the same Creative Commons licence is included and the original work is properly cited. The written permission of Cambridge University Press must be obtained for commercial re-use.
} 
impacted employee well-being, job productivity, and relational satisfaction at work, all of which constitute the focus of this study.

Previous research has suggested that an organization's capacity to build resilience and successfully manage crises depends largely on its ability to capitalize on employee resilience (Näswall, Kuntz, Hodliffe, \& Malinen, 2013). By examining employees' experiences during this massive global upheaval, this study is apt to test the robustness of existing resilience constructs and known relationships. Many COVID-19 studies in organizational settings focused on work performance (e.g., Aguiar-Quintana, Nguyen, Araujo-Cabrera, \& Sanabria-Díaz, 2021; Fischer, Reade, \& Schmal, 2021; Feng \& Savani, 2020) and only a few explored employee relationships (e.g., Bulińska-Stangrecka and Bagieńska, 2021). Thorough searches on Google Scholar and relevant electronic databases (i.e., Academic Search Complete, Business Source Complete, Communication Source, EconLit, PsycInfo, and Vocational and Career Collection) using such keywords as resilience, COVID-19, productivity, workgroup satisfaction, and similar terms revealed only a few studies that empirically examined the impact of resilience on both task outcomes (i.e., productivity) and relationship outcomes (i.e., satisfaction with coworkers) of employees across countries during the early days of the pandemic (e.g., Prochazka et al., 2020). In addition, results on the association between personality traits and mental health during the pandemic are currently inconclusive (Wijngaards, Sisouw de Zilwa, \& Burger, 2020). Ungar (2013, 2017) also noted that much of the research on resilience is grounded in a Western-centric value system that often ignores cultural dimensions and called for an incorporation of culture into resilience research. Hence, this study examines the direct and indirect effects of resilience on both productivity and workplace relational satisfaction through the mediating role of wellbeing during the early stages of the COVID-19 pandemic. We also investigate how the effect of employee resilience is moderated (i.e., dampened or amplified) by personality type and culture when controlling for organizational variables (i.e., job rank, employment duration, and organizational size) and individual demographics (i.e., age, gender, and education). In doing so, we address calls for organizational researchers to help individuals and organizations mitigate and manage adverse impacts of COVID-19 on psychological well-being as well as task and relational dimensions of organizational outcomes (Kniffin et al., 2021; Stephens et al., 2020).

Considering recent negative economic trends coupled with predictions of a long-term global recession from COVID-19, this research is poised to provide organizational leaders with valuable insight into how best to support different employee personality types, ensure employees' psychological well-being, maintain or boost productivity, and promote enduring positive workplace relationships. Drawing on social cognitive theory (SCT), we adopt a cross-cultural examination by contrasting three different countries (i.e., the United States, Croatia, and Thailand) to understand how employees from these cultures responded to workplace disruptions at the onset of the pandemic, while also contributing new insight into the employee resilience literature. We now outline the theoretical framework for this research.

\section{Social cognitive theory and employee resilience}

Resilience, broadly defined as positive adaptation in the face of adversity (Fleming \& Ledogar, 2008), first received scholarly attention in the 1970s when developmental and clinical psychologists examined why some children were harmfully affected by adverse experiences whereas others thrived despite them (e.g., Garmezy, 1971). Within the organizational context, researchers have studied resilience mainly as: (1) an individual trait or capacity and (2) a process (Cheng, King, \& Oswald, 2020). Although the former regards resilience as an individual characteristic leading to positive responses to adversity (Smith, Dalen, Wiggins, Tooley, Christopher, \& Bernard, 2008), the latter focuses on the dynamic processes under which resilience develops and evolves (McLarnon \& Rothstein, 2013). Organizational researchers have also examined resilience at various levels of analysis including employee resilience, team resilience, and organizational resilience (Hartmann, Weiss, 
Newman, \& Hoegl, 2020). In this study, we focus on employee resilience and regard it as a state-like developable individual capacity (Luthans, Avolio, Avey, \& Norman, 2007) that is simultaneously influenced by internal (i.e., personality) and external factors (i.e., cultural contexts) (Herrenkohl, 2013; Näswall et al., 2013). In line with Smith et al. (2008), we define resilience as the ability to bounce back in the face or wake of adversity and focus on how individual employees' ability to withstand challenges shapes their organizational experience during the COVID-19 pandemic.

This view of resilience aligns with SCT which explains psychosocial functioning in terms of the dynamic, reciprocal, and continuous relationships between personal factors, environmental influences, and behavior (Bandura, 1988). All three elements interact with and upon one another to determine behavior (Bandura, 2001). A linchpin of SCT is the concept of self-efficacy or one's belief in one's own ability to persevere or accomplish goals across challenging situations (Lightsey, 2006). Researchers have acknowledged the close connection between self-efficacy and resilience (Lightsey, 2006; Milaković, 2021; Ojo, Fawehinmi, \& Yusliza, 2021; Schwarzer \& Warner, 2013) and suggested that a generalized belief in one's self-efficacy is a central component of resilience and posttraumatic growth (Hamill, 2003; Lightsey, 2006; Schwarzer \& Warner, 2013). Furthermore, Bandura (1988) argues that SCT provides guidelines for equipping people with a resilient sense of efficacy that promotes their psychological well-being and personal accomplishments. Hence, SCT can serve as a helpful framework for examining resilience in the workplace (Hartmann et al., 2020; Lightsey, 2006). In the context of COVID-19, it is likely that employees' resilience would interact with their personality and culture to shape their psychological well-being which, in turn, predict their task and relational outcomes at work.

It has been theorized that resilient individuals have a repertoire of promotive personal resources (e.g., self-efficacy, optimism, and emotional regulation) or environmental resources (e.g., organizational practices and social support) that they utilize to manage and ultimately transcend adverse events (Hartmann et al., 2020; Youssef \& Luthans, 2007). Resilient employees possess characteristics such as enthusiasm, hope, a high degree of autonomy, self-awareness, flexibility and adaptability, a sense of confidence, and the ability to find meaning from challenging situations (Ojo, Fawehinmi, \& Yusliza, 2021; Parker, Jimmieson, Walsh, \& Loakes, 2015). Empirical research has found positive relationships between employee resilience and work happiness, job satisfaction (Youssef \& Luthans, 2007), job performance (Luthans et al., 2007), and work engagement (Mache, Vitzthum, Wanke, David, Klapp, \& Danzer, 2014). Employee resilience has also been linked with fewer interpersonal counterproductive work behaviors and lower emotional exhaustion (Shoss, Jiang, \& Probst, 2018). Evidently, resilience is vital for coping with stress and staying in balance amid the multifaceted challenges presented by COVID-19 (Vinkers et al., 2020).

\section{Well-being, productivity, and relational satisfaction during COVID-19}

During the onset of the COVID-19 pandemic in 2020, many were suddenly forced to work from home, quickly adapt to new platforms and technologies, and balance work-life responsibilities (Ojo, Fawehinmi, \& Yusliza, 2021). Some even confronted impending decreases in work hours and job termination (Mojtahedi et al., 2021). All these drastic workplace changes increased emotional stress and concerns for the health and safety of loved ones as well as oneself (Kocjan, Kavčič, \& Avsec, 2021; Xiong et al., 2020). Previous research has suggested stressors such as these are likely to lower employee well-being (Mojtahedi et al., 2021; Zacher \& Rudolph, 2021), and in turn decrease job productivity (Toscano \& Zappalà, 2020) and strain workplace relationships (Kaushik \& Guleria, 2020). Against this backdrop, this study focuses on three outcome variables pertinent to workers worldwide during the early days of the COVID-19 pandemic: psychological well-being, productivity, and relational satisfaction at work (Galanti, Guidetti, Mazzei, Zappalà, \& Toscano, 2021; Kaushik \& Guleria, 2020; Kniffin et al., 2021).

In this study, psychological well-being is defined as one's levels of positive affective states, functioning, and quality of life (Topp, Østergaard, Søndergaard, \& Bech, 2015; Winefield, Gill, 
Taylor, \& Pilkington, 2012). The impact of COVID-19 on employee well-being has been well-documented with multiple studies reporting an increase in employees' anxiety, depression, and stress compared to the pre-pandemic era (Labrague \& De los Santos, 2020; Mojtahedi et al., 2021; Zacher \& Rudolph, 2021).

Productivity refers to one's ability to concentrate and accomplish work (Koopman et al., 2002). Previous research has indicated that, during lockdowns, women reported lower work productivity compared to men due to increased housework and childcare (Feng \& Savani, 2020). Also, Galanti et al. (2021) found that employees' family-work conflict and social isolation were negatively associated, while self-leadership and autonomy were positively related, with work from home productivity. A recent study found that soccer players - among the fittest individuals - faced a substantial and persistent drop in their work performance by $5 \%$ after an infection with COVID-19 and this negative effect seems to create spillovers on team performance. The researchers suggest that COVID-19 is likely to remain an important, long-term impact on productivity (Fischer, Reade, \& Schmal, 2021).

Relational satisfaction at work concerns how content or satisfied one is with workplace social relationships (Cammann, Fichman, Jenkins, \& Klesh, 1983). Positive relations at work are characterized by high-quality interactions between coworkers and contribute to job satisfaction (Bulińska-Stangrecka \& Bagieńska, 2021), organizational commitment (Lee, Teng, \& Chen, 2015), organizational citizenship behavior (Lam \& Lau, 2012), employee motivation, and intention to stay (Basford \& Offermann, 2012), to name a few. With the increase in remote working, job stress, and limited social connections caused by the pandemic (Bulińska-Stangrecka \& Bagieńska, 2021), it is likely that employees face more communication barriers (e.g., lack of feedback or work-related information), experience workplace loneliness (Çolak \& Çetin, 2021; Lam \& Lau, 2012), and feel less satisfied with their work groups (Andel, Shen, \& Arvan, 2021; Venkataramani, Labianca, \& Grosser, 2013).

Taken together, employees' decreased well-being, lowered productivity, and unsatisfactory workplace relationships can negatively impact team collaboration and eventually organizations' bottom line (Donald, Taylor, Johnson, Cooper, Cartwright, \& Robertson, 2005; Harter, Schmidt, \& Keyes, 2003; Lam \& Lau, 2012). Consequently, it is critical to identify factors that can promote positive mental health at work while also maintaining productivity and satisfactory workplace relationships during this global crisis. Previous research has shown that resilience is positively related to employee well-being (Britt, Shen, Sinclair, Grossman, \& Klieger, 2016) and buffers employees from negative experiences, enabling them to maintain high levels of motivation and productivity despite disruptions (Hartmann et al., 2020). Resilient individuals are also able to maintain a positive outlook and boost morale, which can facilitate the collective coping process (Tugade \& Fredrickson, 2004) and promote relational health (Afifi, Merrill, \& Davis, 2016). We, therefore, pose:

Hypothesis 1: Employee resilience will be positively associated with (a) psychological well-being, (b) productivity, and (c) relational satisfaction at work during the COVID-19 pandemic.

In addition to the direct effect of resilience on productivity and relational satisfaction, this study will also examine the indirect effect of resilience through the mediating role of well-being. Rodrigues (2019) reported that work engagement, as a positive construct of well-being, mediated the relationship between resilience and performance. Similarly, well-being has been associated with productivity (Koopman et al., 2002) and positive social interaction at work (Stoll, Michaelson, \& Seaford, 2012). Therefore, we postulate that resilience will boost psychological well-being which, in turn, will positively predict workplace productivity and relational satisfaction with coworkers. Hence:

Hypothesis 2: Psychological well-being will mediate the relationship between employee resilience and (a) productivity, and (b) relational satisfaction at work during the COVID-19 pandemic. 


\section{Personality}

Although personality traits are inherent in an individual's nature and can be difficult to change, studies have shown that they can impact how individuals adapt to episodic and ongoing stress alike (Löckenhoff, Terracciano, Patriciu, Eaton, \& Costa, 2009), including their well-being at work (Zeidner, Hadar, Matthews, \& Roberts, 2013), resilience during stressful events (Carver \& Connor-Smith, 2010), job performance (Hurtz \& Donovan, 2000), and the development of interpersonal relationships at work (Hough \& Furnham, 2003). Goldberg (1990) suggests that personality comprises five dimensions, namely: extraversion (being talkative and outgoing), agreeableness (being sympathetic and warm), neuroticism (being short-tempered and unstable), conscientiousness (being organized and prompt), and openness to experience (being creative and curious). This study considers one of these personality dimensions that has a well-established connection with an individual's resilience following a traumatic event: extraversion (Judge, Higgins, Thoresen, \& Barrick, 1999).

According to Jung (1971), extraversion and introversion are the major orientations of personality. An individual's extraversion-introversion preference is determined by the way in which they direct their general interest; with extraverts focusing on the external and introverts focusing on the internal. Extraversion is characterized by excitability, sociability, talkativeness, assertiveness, and high amounts of emotional expressiveness (Power \& Pluess, 2015). People who are high in extraversion tend to seek out social stimulation and opportunities to engage with others. On the contrary, those who are low in extraversion (or introverted) tend to be more reserved and less involved in social situations (Condon \& Ruth-Sahd, 2013).

Previous examinations on the relationship between extraversion and mental health during COVID-19 have reported conflicting findings. For example, Nikčević, Marino, Kolubinski, Leach, and Spada (2021) found that extraversion was linked with decreased anxiety whereas Kocjan, Kavčič, and Avsec (2021) and Zacher and Rudolph (2021) reported extraversion was linked with increased stress. Also, Wijngaards, Sisouw de Zilwa, and Burger (2020) suggested that introverts fare better than extroverts when living with governments' imposed stringent measures. These inconclusive findings may be attributable to the exceptional circumstances of the pandemic and the stringent measures (e.g., lockdowns and social distancing) imposed to curb the spread of the virus (Kocjan, Kavčič, \& Avsec, 2021). Also, research on the relationship between personality and work productivity during COVID-19 is still limited (Günaydin, 2021). Similarly, we have yet to understand if or to what extent satisfaction with workplace relationships varies by personality type during the early days of the pandemic (Biron, Peretz, \& Turgeman-Lupo, 2020; Kaushik \& Guleria, 2020).

From the SCT perspective, personality may influence how individuals assess their efficacy (or resilience) which would then determine their behavior (Hartmann et al., 2020; Lightsey, 2006). Researchers have identified several traits of extraversion that can predict an individual's behavior. For instance, extraverted individuals experience more positive emotions (Watson \& Clark, 1992). They also tend to be more assertive, dominant, and ambitious, and are generally perceived as more successful leaders (Zopiatis \& Constanti, 2012). Their tendency to reappraise and reframe problems in a positive light when faced with stress (Carver \& Connor-Smith, 2010) protects extraverts from experiencing burnout (Bakker, Van der Zee, Lewig, \& Dollard, 2006). High levels of extraversion have been linked to post-traumatic growth among emergency service workers (Shakespeare-Finch, Gow, \& Smith, 2005), and extraverted women also display resilience that enables them to pursue career advancement (Khalid \& Sekiguchi, 2019). Additionally, extraverted managers are more likely to display agency-related characteristics (e.g., assertiveness, activity, ambition, and persuasiveness) and thus perform better than introverted managers (Minbashian, Bright, \& Bird, 2009). Because they tend to be social and bold in nature, extraverted individuals form and maintain interpersonal relationships at work, and perceive those relationships to be of higher quality (Kalish \& Robins, 2006). Following these past studies, we hypothesize: 
Hypothesis 3: Extraverted individuals will report higher levels of (a) well-being, (b) productivity, and (c) relational satisfaction at work during the COVID-19 pandemic.

\section{Interactive effects of resilience, personality, and culture}

An individual's unique adaptation to a traumatic event is an interaction between personality and the trauma context (Saakvitne, Tennen, \& Affleck, 1998). According to SCT, 'employees are producers of their personality, behavior, and environment, yet at the same time are products of it' (Hartmann et al., 2020, p. 946). Therefore, an investigation of employee resilience as a developable capacity must necessarily also consider how personality and cultural factors might moderate the impact of resilience. Since extraversion is closely linked to positive reappraisal, which then fosters resilience, it is likely that extraverted employees with high resilience will exhibit greater well-being (Carver \& Connor-Smith, 2010), productivity (Minbashian, Bright, \& Bird, 2009), and relational satisfaction compared to introverted employees (Kalish \& Robins, 2006). The moderating effect of culture is also highly likely given the strong relationships between specific cultural dimensions and resilience. For example, employees with high horizontal collectivism values were found to be more resilient to workplace incivility, while those with high horizontal individualism values displayed less resilience (Welbourne, Gangadharan, \& Sariol, 2015). Also, previous research has shown that collectivistic orientations are positively associated with employee wellbeing (Brougham \& Haar, 2013; Rego \& Cunha, 2009), productivity (Papamarcos, Latshaw, \& Watson, 2007; Tjosvold, Law, \& Sun, 2003), and satisfaction at work (Hui, Yee, \& Eastman, 1995). To examine how cultural differences might moderate the effect of employee resilience during the COVID-19 pandemic, we strategically selected the United States, Croatia, and Thailand for the following reasons.

First, the three countries hold different cultural values (Hofstede, 1980). Based on Hofstede's cultural dimensions model, the United States generally scores much lower on power distance and much higher on individualism than both Croatia and Thailand. Most US organizations prioritize competition, achievement, and success reflecting high masculinity. By comparison, Croatia and Thailand are more collectivistic societies with higher power distance and uncertainty avoidance. Croatians and Thais generally tend to prioritize caring for others and loyalty to one's community, accepting hierarchical structures, and following orders. Furthermore, Croatia and Thailand are typically described as more feminine cultures, meaning that employees tend to favor both team solidarity and the overall well-being of their work lives, as well as leisure time and flexible schedules (Hofstede Insights., 2020).

Second, each of these countries has displayed a markedly different response to the COVID-19 pandemic using a different disease control measure. As of April 1, 2020, Croatia scored 96.30, Thailand scored 68.06, and the United States scored 72.69 on the COVID-19 Government Response Stringency Index which measures the variation in governments' response to COVID-19 based on public policies such as workplace closures, travel bans, cancellation of public events, stay-at-home orders, etc. on a 0-100 scale (Hale et al., 2021). These government responses play a role in mental health as a large-scale survey covering 58 countries at the onset of the COVID-19 pandemic revealed that citizens' perception of an insufficient public and government response was associated with lower mental well-being (Fetzer et al., 2020). Also, the United States currently registers the highest number of positive cases and COVID-19 deaths (World Health Organization, 2021). By comparison, Croatia and Thailand were more successful in 'flattening the curve' (Stevis-Gridneff, 2020).

A third factor that enabled selecting these particular countries is that two authors hail from these countries and therefore had access to research participants in Croatia and Thailand. These three countries collectively present distinct regional snapshots of employee experiences during COVID-19 across three continents. Aligned with SCT's proposition that human behavior is determined by personal and environmental factors, it is likely that the effect of employees' 


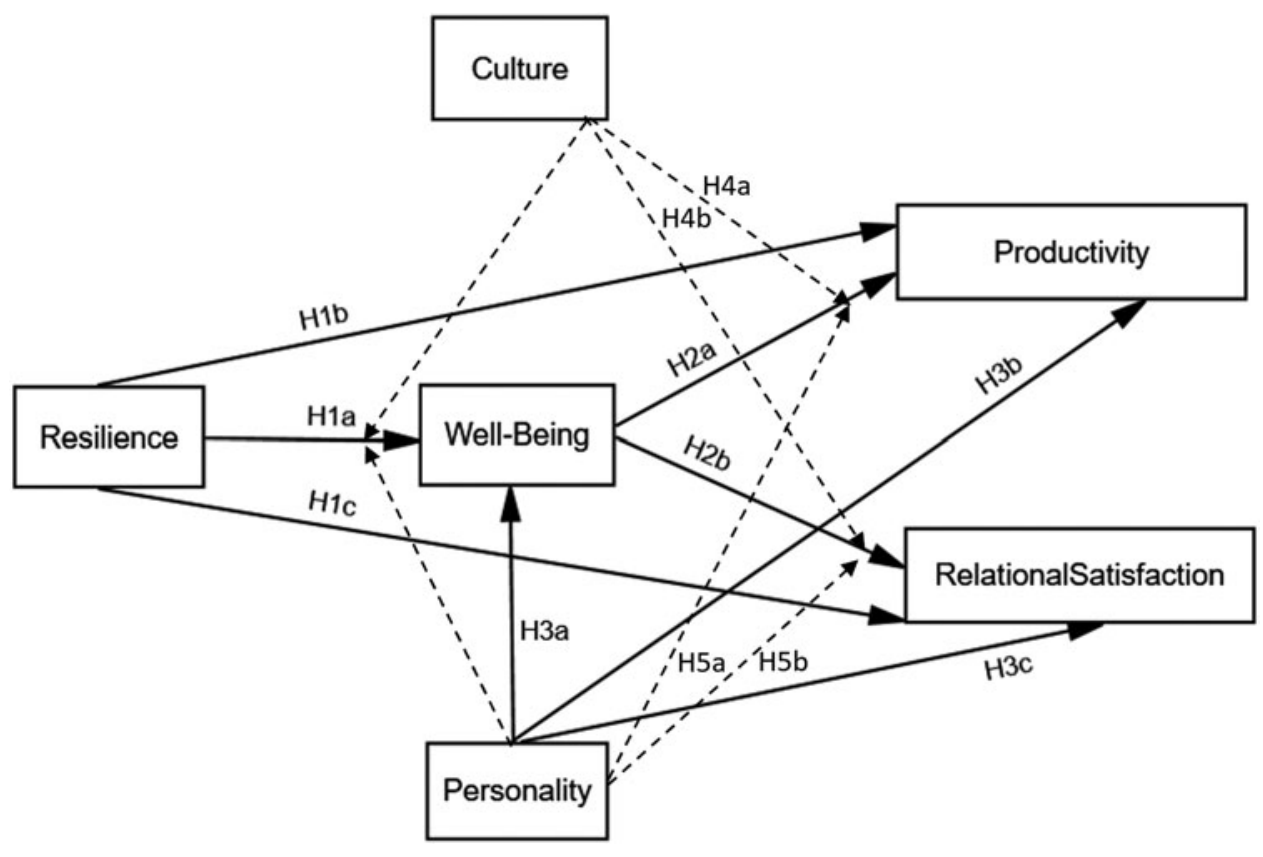

Figure 1. Hypothesized model.

resilience on positive outcomes will be moderated or vary by their culture and personality type. Therefore, we propose a hypothesized model shown in Figure 1:

Hypothesis 4: During the COVID-19 pandemic, culture will moderate the indirect effect of resilience on (a) productivity and (b) relational satisfaction at work through the mediating role of psychological well-being.

Hypothesis 5: During the COVID-19 pandemic, personality type will moderate the indirect effect of resilience on (a) productivity and (b) relational satisfaction at work through the mediating role of psychological well-being.

\section{Control variables: job rank, employment duration, organizational size, and demographic variables}

Previous research has suggested a positive impact of job titles on productivity (Martinez, Laird, Martin, \& Ferris, 2008) and job satisfaction (Al-Zoubi, 2012). Additionally, some argue that job tenure is associated with better job performance because employees gained more tacit knowledge about how to perform their jobs effectively over time (Schmidt, Hunter, \& Outerbridge, 1986). Furthermore, research (New Economics Foundation., 2014) suggests that individuals within smaller organizations report higher levels of well-being at work than those working for larger organizations. Moreover, previous studies examining the impact of COVID-19 on mental health found a positive relationship between age and subjective well-being (Kocjan, Kavčič, \& Avsec, 2021; Xiong et al., 2020). Women also reported higher levels of mental health problems compared to men (Kocjan, Kavčič, \& Avsec, 2021; Plomecka et al., 2020; Rossi et al., 2020; Xiong et al., 2020) and the participants with higher levels of education reported higher subjective well-being compared to those with lower education (Kocjan, Kavčič, \& Avsec, 2021). These findings suggest that job rank, employment duration, organizational size, age, gender, and education 
may influence our dependent variables (DVs). Therefore, we will account for these organizational and demographic variables to assess more accurately how much variance in productivity and relational satisfaction is attributable to resilience and well-being, as well as all interactions.

\section{Method}

\section{Participants}

This is part of a larger international research project about the impact of the COVID-19 pandemic on various aspects of life. The data reported in this paper concern workplace settings and include a total of 832 participants from the United States $(n=321)$, Croatia $(n=265)$, and Thailand $(n=246)$. Participants were working adults with a full-time or part-time job and held various job positions ranging from entry-level to company ownership at small to large organizations from various industries. Within the US sample, approximately $82 \%$ of participants self-identified as Caucasian, $4 \%$ as Black/African American, 3\% as Asian, 2\% as Hispanic/Latino, $6 \%$ as multiracial, and the remainder $(2 \%)$ did not identify their ethnicity. All other demographic characteristics are detailed in Table 1.

\section{Procedures}

Following Institutional Review Board approval, participants were recruited using convenience and snowball/network sampling. Recruitment channels included personal email invitations, social media platforms (LinkedIn, Reddit, Facebook groups dealing with COVID-19 as well as Facebook ads), and public listservs of professional organizations. Potential participants were asked to complete an online questionnaire and forward it to coworkers. No incentive was provided for participation. Questionnaires were administered in English, Croatian, and Thai. The Croatian and Thai questionnaires were translated by two of the authors and cross-verified by other native Croatian and Thai speakers, respectively, to ensure translational integrity and linguistic equivalence. Data were collected in April and May 2020.

\section{Confirmatory factor invariance analysis (CFIA)}

An initial CFIA was conducted using SPSS AMOS 26 to ensure the validity of the focal measures and assess whether the measurement model - comprising resilience, well-being, productivity, and relational satisfaction - could viably be applied to all three cultures. The result indicated that the measurement weights model was significantly different from the unconstrained model, and five scale items (two from the productivity scale and three from the resilience scale) had significantly unequal standardized regression weights across the three samples. This suggested that participants from the three cultures had interpreted those five items differently. Therefore, these items were removed and another CFIA was performed. The revised model fit the data well. The unconstrained model was statistically significant $\left(\chi^{2}=441.914, d f=252, p<.000\right.$, $\mathrm{TLI}=.960, \mathrm{CFI}=.978, \mathrm{RMSEA}=.031, \mathrm{SRMR}=.039)$ and no significance was found between the unconstrained model and the measurement weights model, $\chi_{\text {Diff }}^{2}=30.975, d f=22, p=.097$. All scale items were also significant and had acceptable to robust standardized regression weights ranging from .54 to .91 (Stevens, 2012) and acceptable Cronbach's alpha reliability ranging from .72 to .92 (Taber, 2018). The final scales (see Table 2) included the following.

\section{Measures}

The questions used for this paper included multiple-choice questions concerning personal and work demographics and Likert-type scales to measure the variables of interest. 
Table 1. Demographic Characteristics $(N=832)$

\begin{tabular}{|c|c|c|c|c|c|c|}
\hline \multirow[b]{2}{*}{ Characteristics } & \multicolumn{2}{|c|}{ United States } & \multicolumn{2}{|c|}{ Croatia } & \multicolumn{2}{|c|}{ Thailand } \\
\hline & $n$ & $\%$ & $n$ & $\%$ & $n$ & $\%$ \\
\hline Age & \multicolumn{2}{|c|}{$\begin{array}{l}M=40.16 \\
S D=13.84 \\
\text { Range }=18-71\end{array}$} & \multicolumn{2}{|c|}{$\begin{array}{l}M=39.69 \\
S D=9.47 \\
\text { Range }=20-62\end{array}$} & \multicolumn{2}{|c|}{$\begin{array}{l}M=39.64 \\
S D=9.33 \\
\text { Range }=20-66\end{array}$} \\
\hline \multicolumn{7}{|l|}{ Sex } \\
\hline Male & 90 & 28.00 & 72 & 27.20 & 116 & 47.20 \\
\hline Female & 227 & 70.70 & 188 & 70.90 & 127 & 51.60 \\
\hline Prefer not to say & 3 & .90 & 2 & .80 & 3 & 1.20 \\
\hline \multicolumn{7}{|l|}{ Personality } \\
\hline Introversion & 144 & 44.90 & 78 & 29.40 & 125 & 50.80 \\
\hline Extraversion & 176 & 54.80 & 186 & 70.20 & 118 & 48.00 \\
\hline \multicolumn{7}{|l|}{ Education } \\
\hline Less than bachelor's degree & 44 & 13.70 & 107 & 40.40 & 33 & 13.40 \\
\hline Bachelor's degree & 76 & 23.70 & 48 & 18.10 & 108 & 43.90 \\
\hline Master's degree & 99 & 30.80 & 82 & 30.90 & 91 & 37.00 \\
\hline Doctoral degree or equivalent & 101 & 31.50 & 18 & 6.80 & 14 & 5.70 \\
\hline \multicolumn{7}{|l|}{ Job rank } \\
\hline Intern/entry level/clerical/blue collar & 58 & 18.10 & 148 & 55.80 & 28 & 11.40 \\
\hline Analyst/associate & 22 & 6.90 & 39 & 14.70 & 70 & 28.50 \\
\hline Professional & 173 & 53.90 & 19 & 7.20 & 40 & 16.30 \\
\hline Management & 55 & 17.10 & 35 & 13.20 & 57 & 23.20 \\
\hline Owner & 13 & 4.00 & 24 & 9.10 & 51 & 20.70 \\
\hline \multicolumn{7}{|l|}{ Employment duration } \\
\hline Less than a year & 60 & 18.70 & 23 & 8.70 & 26 & 10.60 \\
\hline $1-3$ years & 104 & 32.40 & 74 & 27.90 & 58 & 23.60 \\
\hline $4-6$ years & 63 & 19.60 & 45 & 17.00 & 39 & 15.90 \\
\hline 7-9 years & 25 & 7.80 & 21 & 7.90 & 40 & 16.30 \\
\hline 10 years or over & 68 & 21.20 & 102 & 38.50 & 81 & 32.90 \\
\hline \multicolumn{7}{|l|}{ Organizational size } \\
\hline Up to 100 employees & 93 & 29.00 & 181 & 68.30 & 125 & 50.80 \\
\hline 100 to 300 employees & 44 & 13.70 & 31 & 11.70 & 37 & 15.00 \\
\hline More than 300 employees & 184 & 57.30 & 52 & 19.60 & 82 & 33.30 \\
\hline \multicolumn{7}{|l|}{ Industries } \\
\hline $\begin{array}{l}\text { Arts, entertainment, and recreation, } \\
\text { accommodation, and food service }\end{array}$ & 15 & 4.70 & 14 & 5.30 & 10 & 4.10 \\
\hline $\begin{array}{l}\text { Construction, manufacturing, transportation, } \\
\text { and warehousing }\end{array}$ & 17 & 5.30 & 31 & 11.70 & 33 & 13.40 \\
\hline Education services & 158 & 49.20 & 33 & 12.50 & 33 & 13.40 \\
\hline
\end{tabular}


Table 1. (Continued.)

\begin{tabular}{|c|c|c|c|c|c|c|}
\hline \multirow[b]{2}{*}{ Characteristics } & \multicolumn{2}{|c|}{ United States } & \multicolumn{2}{|c|}{ Croatia } & \multicolumn{2}{|c|}{ Thailand } \\
\hline & $n$ & $\%$ & $n$ & $\%$ & $n$ & $\%$ \\
\hline $\begin{array}{l}\text { Professional, scientific, management, } \\
\text { administrative, and technical services }\end{array}$ & 32 & 10.00 & 46 & 17.40 & 28 & 11.40 \\
\hline Healthcare and social assistance & 18 & 5.60 & 29 & 10.90 & 9 & 3.70 \\
\hline Wholesale and retail trade & 7 & 2.20 & 23 & 8.70 & 22 & 8.90 \\
\hline $\begin{array}{l}\text { Government, public administration, military, } \\
\text { police, public services }\end{array}$ & 16 & 5.00 & 10 & 3.80 & 46 & 18.70 \\
\hline Others & 52 & 16.20 & 34 & 12.80 & 48 & 19.50 \\
\hline Total & 321 & 100 & 265 & 100 & 246 & 100 \\
\hline
\end{tabular}

Note: Some variables do not add up to $100 \%$ due to missing data.

\section{Resilience}

Three items from Smith et al.'s (2008) unidimensional Brief Resilience Scale (BRS) were used to measure participants' ability to bounce back or recover from stressful events. The BRS is a widely used resilience scale (ranging from strongly disagree [1] to strongly agree [5]) with strong psychometric ratings (Windle, Bennett, \& Noyes, 2011). It includes items reflecting behavioral persistence which, following recent research, may be the most relevant to the construct of resilience (Cheng, King, \& Oswald, 2020).

\section{Well-being}

The 5-item World Health Organization Well-Being Index (WHO-5) was employed (World Health Organization, 1998). The WHO-5 is among the most widely used questionnaires to assess subjective psychological well-being and is applicable across disciplines (Topp et al., 2015). The original WHO-5 prompts participants to rate how well each of the five statements (ranging from at no time [1] to all of the time [6]) applies to them within the past 14 days. In this study, we asked participants to consider a full month prior to completing the questionnaire to better capture their well-being during the early stages of the COVID-19 lockdown.

\section{Productivity}

A modified version of the Stanford Presenteeism Scale (SPS-6; Koopman et al., 2002) was used to assess participants' level of productivity during the early stages of the pandemic. Participants indicated their level of agreement (from strongly disagree [1] to strongly agree [5]) with four statements concerning their work experiences in the month prior to completing the questionnaire. The SPS-6 has demonstrated excellent psychometric characteristics (Koopman et al., 2002) and a high degree of reliability and validity suitable for measuring productivity in a diverse employee population (Turpin et al., 2004). The scale captured the ability to avoid distractions and complete work despite health problems. For this study, the phrase 'my [health problem]' in each item was replaced with 'COVID-19.'

\section{Relational satisfaction}

Relational satisfaction was measured using a modified version of Cammann et al.'s (1983) satisfaction with workgroup subscale from the Michigan Organizational Assessment Questionnaire. Previous research using this scale reported high internal reliability (e.g., Venkataramani, Labianca, and Grosser, 2013). Participants indicated their level of agreement (from strongly 
Table 2. Standardized regression weights for confirmatory factor analysis and internal reliabilities of all scales by culture

\begin{tabular}{|c|c|c|c|}
\hline \multirow[b]{2}{*}{ Scale } & \multicolumn{3}{|c|}{ Standardized regression weights } \\
\hline & $\begin{array}{l}\text { United } \\
\text { States }\end{array}$ & Croatia & Thailand \\
\hline \multicolumn{4}{|l|}{ Resilience } \\
\hline I tend to bounce back quickly after hard times. & .82 & .81 & .84 \\
\hline It does not take me long to recover from a stressful event. & .79 & .75 & .82 \\
\hline $\begin{array}{l}\text { I tend to take a long time to get over setbacks in my life. } \\
\text { (reverse-coded) }\end{array}$ & .83 & .79 & .58 \\
\hline Internal Reliability (Cronbach's alpha) & .85 & .82 & .78 \\
\hline \multicolumn{4}{|l|}{ Well-Being } \\
\hline 1. I have felt cheerful and in good spirits. & .85 & .89 & .87 \\
\hline 2. I have felt calm and relaxed. & .83 & .91 & .84 \\
\hline 3. I have felt active and vigorous. & .79 & .81 & .86 \\
\hline 4. I woke up feeling fresh and rested. & .74 & .80 & .85 \\
\hline 5. My daily life has been filled with things that interest me. & .78 & .76 & .78 \\
\hline Internal Reliability (Cronbach's alpha) & .90 & .92 & .92 \\
\hline \multicolumn{4}{|l|}{ Productivity } \\
\hline 1. Despite COVID-19, I was able to finish hard tasks in my work. & .64 & .58 & .65 \\
\hline $\begin{array}{l}\text { 2. At work, I was able to focus on achieving my goals despite } \\
\text { COVID-19. }\end{array}$ & .74 & .66 & .74 \\
\hline $\begin{array}{l}\text { 3. Because of COVID-19, the stresses of my job were much harder to } \\
\text { handle. }\end{array}$ & .54 & .74 & .54 \\
\hline 4. COVID-19 distracted me from taking pleasure in my work. & .61 & .69 & .61 \\
\hline Internal Reliability (Cronbach's alpha) & .72 & .77 & .73 \\
\hline \multicolumn{4}{|l|}{ Relational Satisfaction } \\
\hline 1. I have been satisfied with my work group. & .88 & .89 & .80 \\
\hline $\begin{array}{l}\text { 2. I look forward to working with the members of my work group each } \\
\text { day. }\end{array}$ & .82 & .77 & .55 \\
\hline 3. I have been satisfied with the way I am treated by my coworkers. & .82 & .84 & .79 \\
\hline Internal Reliability (Cronbach's alpha) & .88 & .87 & .75 \\
\hline
\end{tabular}

disagree [1] to strongly agree [5]) with three statements about how they felt toward coworkers in the month prior to completing the questionnaire.

\section{Personality type}

Two extraversion items were adapted from Gosling, Rentfrow, and Swann's (2003) widely used 10-Item Personality Inventory (TIPI). However, due to an error in survey design, the personality question was formatted as a multiple-choice rather than the original Likert scale. Participants responded to the question, 'How well do the following statements describe your personality? I see myself as someone who is...' by self-identifying as either 'outgoing/social' (i.e., extravert) or 'reserved' (i.e., introvert). This measurement of extraversion as a binary rather than continuous variable posed a limitation to the findings which will be later discussed. 


\section{Data analysis}

To test the hypotheses, a series of moderated mediation analyses were performed using Hayes' (2017) PROCESS macro version 3.5. Two moderated mediation analyses were run using model 10 with 5,000 bootstrap samples and 95\% confidence intervals (CIs). In the first analysis, resilience was specified as the independent variable; well-being as the mediator; culture and personality as the moderators; productivity as the DV; and job rank, employment duration, organizational size, age, gender, and education (dummy-coded) as the covariates. The second analysis followed the same procedure, except that relational satisfaction was specified as the DV. In both analyses, the 'indicator' coding system was first used for culture, which created two comparison groups: (1) Croatia versus United States and (2) Thailand versus United States. Then, the 'Helmert' coding system was used which compared: (1) Croatia and Thailand versus United States and (2) Thailand versus Croatia.

\section{Results}

This study was conducted during the early stages of the COVID-19 pandemic. It examined the direct and indirect effects of resilience on productivity and relational satisfaction through well-being when moderated by personality and culture and accounting for job rank, employment duration, organizational size, age, gender, and education. Descriptive statistics and correlation coefficients of continuous variables are shown in Table 3.

\section{Hypotheses 1 and 2: direct and indirect effects of resilience}

Hypothesis 1 postulated a positive, direct effect of employee resilience on well-being (hypothesis 1a), productivity (hypothesis $1 \mathrm{~b}$ ), and relational satisfaction (hypothesis 1c). Controlling for the influence of other predictors and the interaction effects in the model (see Table 4), resilience significantly and positively predicted well-being (indicator: $b=.41$, Helmert: $b=.51$ at $p<.001$ ), thus supporting hypothesis 1a. Of note, the effects of resilience on well-being had the same pattern across all three countries and two personality types (i.e., the higher resilience and the higher well-being) (see Figure 2). Also, resilience was found to positively predict productivity, but only with a small effect size $(b=.13, p=.02)$ through the Helmert coding system (i.e., comparing Croatia and Thailand collectively against the United States, and comparing Thailand against Croatia). No significance $(b=.01, p=.82)$ was found for the relationship between resilience and productivity when the indicator coding was used (i.e., comparing Croatia and Thailand individually against the United States). Hence, hypothesis $1 \mathrm{~b}$ was only partially supported. Finally, resilience positively predicted relational satisfaction (indicator: $b=.201$, Helmert: $b=.168$ ) both at $p<.001$, therefore hypothesis $1 \mathrm{c}$ was supported.

Hypothesis 2 concerned the mediating effect of well-being between employee resilience and productivity (hypothesis $2 \mathrm{a}$ ) and relational satisfaction (hypothesis $2 \mathrm{~b}$ ), respectively. The results (Table 4$)$ showed well-being positively predicted both productivity $(b=.41, p<.001)$ and relational satisfaction $(b=.22, p<.001)$. To determine the indirect effect of resilience through wellbeing, a simple mediation analysis (PROCESS Model 4) was first conducted. The unstandardized indirect effect of resilience on productivity through the mediating role of well-being was .25 (boot $\mathrm{SE}=.02,95 \%$ boot $\left.\mathrm{CI}=[20,30]), F(2,793)=185.84, p<.001, r^{2}=.32\right)$. The unstandardized indirect effect of resilience on relational satisfaction through the mediating role of well-being was .11 (boot $\mathrm{SE}=.02,95 \%$ boot $\left.\mathrm{CI}=[07,16]), F(2,798)=50.99, p<.001, r^{2}=.11\right)$. Additionally, the moderated mediation model consistently revealed well-being exerted a significant mediating effect in the relationship between resilience and productivity, as well as relational satisfaction, regardless of country or personality type (Table 5). This was evidenced by the fact that bootstrap 95\% CIs of all conditional indirect effects did not include zero. These results indicated that, across countries and personality types, employees' resilience increased their psychological well-being which, in turn, increased their productivity and relational satisfaction. Therefore, both hypotheses $2 \mathrm{a}$ and $2 \mathrm{~b}$ were supported. 
Table 3. Means, standard deviations, and intercorrelations among continuous variables by culture and personality type

\begin{tabular}{|c|c|c|c|c|c|c|c|c|c|c|}
\hline \multirow[b]{2}{*}{ Variable } & \multicolumn{2}{|c|}{ Introverts } & \multicolumn{2}{|c|}{ Extraverts } & \multicolumn{2}{|c|}{ Total } & \multicolumn{4}{|c|}{ Correlations } \\
\hline & $M$ & SD & $M$ & SD & $M$ & SD & 1 & 2 & 3 & 4 \\
\hline \multicolumn{11}{|l|}{ US sample } \\
\hline Resilience & 3.31 & .94 & 3.52 & .87 & 3.43 & .91 & - & & & \\
\hline well-being & 3.36 & 1.12 & 3.43 & 1.13 & 3.40 & 1.12 & $.38^{\star \star}$ & - & & \\
\hline Productivity & 3.14 & .92 & 3.12 & .93 & 3.13 & .92 & $.19^{\star}$ & $.58^{\star \star}$ & - & \\
\hline Relational satisfaction at work & 3.66 & .97 & 4.02 & .91 & 3.86 & .96 & $.26^{\star \star}$ & $.30^{\star \star}$ & $.30^{\star \star}$ & - \\
\hline \multicolumn{11}{|l|}{ Croatian sample } \\
\hline Resilience & 3.18 & 1.01 & 3.54 & 1.00 & 3.43 & 1.02 & - & & & \\
\hline Well-being & 3.61 & 1.22 & 3.75 & 1.25 & 3.71 & 1.24 & $.45^{\star \star}$ & - & & \\
\hline Productivity & 3.50 & .98 & 3.25 & 1.12 & 3.32 & 1.08 & $.41^{\star \star}$ & $.52^{\star \star}$ & - & \\
\hline Relational satisfaction at work & 3.56 & 1.12 & 3.96 & .87 & 3.85 & .96 & $.17^{\star}$ & $.26^{\star \star}$ & $.18^{\star \star}$ & - \\
\hline \multicolumn{11}{|l|}{ Thai sample } \\
\hline 1. Resilience & 3.41 & .85 & 3.65 & .67 & 3.53 & .78 & - & & & \\
\hline 2. Well-being & 3.84 & 1.17 & 4.11 & 1.06 & 3.98 & 1.13 & $.47^{\star \star}$ & - & & \\
\hline 3. Productivity & 3.82 & .87 & 3.55 & .87 & 3.69 & .88 & $.38^{\star \star}$ & $.52^{\star \star}$ & - & \\
\hline 4. Relational satisfaction at work & 3.77 & .81 & 3.88 & .58 & 3.82 & .70 & $.37^{\star \star}$ & $.46^{\star \star}$ & $.34^{\star \star}$ & - \\
\hline
\end{tabular}

${ }^{*} p<.01,{ }^{* *} p<.001$. 
Table 4. Unstandardized direct and covariate effects on well-being, productivity, and relational satisfaction

\begin{tabular}{|c|c|c|c|c|c|c|c|c|c|c|c|c|}
\hline \multirow[b]{2}{*}{ Variables } & \multicolumn{4}{|c|}{ Well-being } & \multicolumn{4}{|c|}{ Productivity } & \multicolumn{4}{|c|}{ Relational satisfaction } \\
\hline & $b$ & SE & $t$ & $p$ & $b$ & $\mathrm{SE}$ & $t$ & $p$ & $b$ & SE & $t$ & $p$ \\
\hline \multicolumn{13}{|l|}{ Direct (main) effects } \\
\hline Resilience (indicator coding) & .40 & .08 & 4.99 & .000 & .01 & .06 & .23 & .818 & .20 & .07 & 2.91 & .004 \\
\hline Resilience (Helmert coding) & .51 & .06 & 7.84 & .000 & .13 & .05 & 2.43 & .015 & .16 & .05 & 2.82 & .005 \\
\hline Well-being & - & - & - & - & .41 & .03 & 14.14 & .000 & .22 & .03 & 7.11 & .000 \\
\hline CR vs. USA & .47 & .11 & 4.37 & .000 & .22 & .08 & 2.62 & .009 & -.05 & .09 & -.59 & .558 \\
\hline TH vs. USA & .53 & .10 & 5.47 & .000 & .37 & .08 & 4.86 & .000 & -.15 & .08 & -1.84 & .066 \\
\hline CR and TH vs. USA & .51 & .09 & 5.84 & .000 & .29 & .07 & 4.37 & .000 & -.10 & .07 & -1.40 & .163 \\
\hline TH vs. CR & .06 & .11 & .51 & .611 & .15 & .09 & 1.71 & .088 & -.10 & .09 & -1.06 & .289 \\
\hline Extraverts vs. introverts & .04 & .08 & .47 & .642 & -.22 & .06 & -3.60 & .000 & .26 & .06 & 4.10 & .000 \\
\hline \multicolumn{13}{|l|}{ Covariate effects } \\
\hline Job rank & .02 & .03 & .71 & .478 & -.03 & .03 & -1.21 & .228 & .04 & .03 & 1.64 & .102 \\
\hline Employment duration & -.03 & .03 & -1.06 & .292 & -.08 & .02 & -3.19 & .002 & -.09 & .03 & -3.47 & .000 \\
\hline Organizational size & .02 & .05 & .34 & .733 & .11 & .04 & 3.16 & .002 & .04 & .04 & .93 & .355 \\
\hline Age & .01 & .00 & 3.26 & .001 & .01 & .00 & 2.22 & .027 & .01 & .00 & 2.83 & .005 \\
\hline Gender & -.10 & .08 & -1.21 & .227 & -.03 & .06 & -.46 & .644 & -.03 & .07 & -.39 & .697 \\
\hline Bachelor's degree & .17 & .12 & 1.48 & .140 & .18 & .09 & 2.05 & .041 & -.06 & .09 & -.64 & .520 \\
\hline Graduate degree & .20 & .11 & 1.82 & .069 & .17 & .09 & 1.98 & .049 & -.15 & .09 & -1.65 & .099 \\
\hline Model fits & \multicolumn{4}{|c|}{$F(14,705)=17.50, r^{2}=.26, p<.001$} & \multicolumn{4}{|c|}{$F(15,704)=28.56, r^{2}=.38, p<.001$} & \multicolumn{4}{|c|}{$F(15,708)=9.83, r^{2}=.17, p<.001$} \\
\hline
\end{tabular}

CR, Croatia; TH, Thailand; USA, United States.

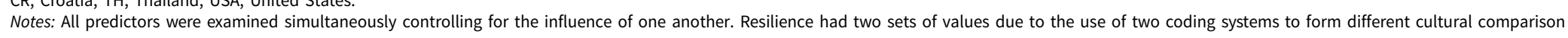
groups. 

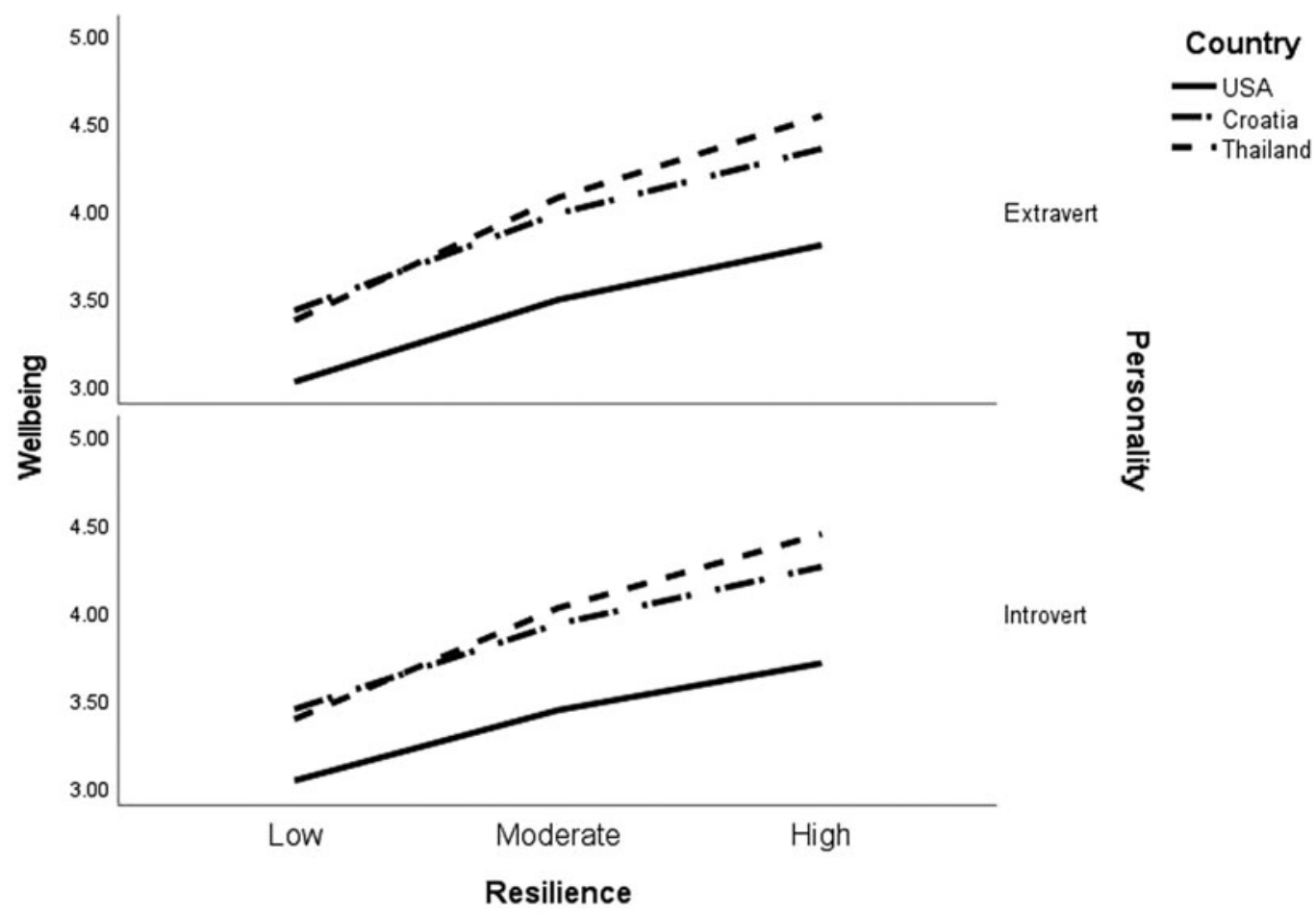

xtravert

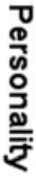

Figure 2. The conditional effect of resilience on well-being by country and personality type.

\section{Hypothesis 3: direct effects of personality}

We predicted that extraverted participants would report higher levels of well-being (hypothesis $3 a)$, productivity (hypothesis $3 \mathrm{~b}$ ), and relational satisfaction (hypothesis $3 \mathrm{c}$ ) than introverted participants during the pandemic. A simple regression analysis revealed a significant positive association of low effect size between extraversion and well-being $(b=.17, \beta=.07, p=.04$, $\left.r^{2}=.005\right)$. However, this direct effect did not hold in the moderated mediation model where all other variables were accounted for $(b=.04, p=.642)$ (see Table 4). Thus, hypothesis 3 a was not supported. Moreover, extraverted participants were reportedly .22 units less productive $(b=-.22, p<.001)$ but .26 units more satisfied with their relationships at work than introverted participants $(b=.26, p<.001)$. These results were consistent in both a simple regression model and moderated mediation model, hence rejecting hypothesis $3 \mathrm{~b}$ but supporting hypothesis $3 \mathrm{c}$.

\section{Hypotheses 4 and 5: moderating effects of personality and culture}

We postulated that culture (hypothesis 4 ) and personality type (hypothesis 5) would moderate the indirect effects of resilience on productivity (a) and relational satisfaction (b) through the mediating role of well-being. In other words, the impacts of employee resilience on productivity and relational satisfaction through well-being might be strengthened or weakened by culture and/ or personality type. The results (Table 4) revealed the direct (main) effects of culture on wellbeing, productivity, and relational satisfaction. Both Croatian and Thai workers reported a higher level of well-being (Croatians: $b=.47, p<.001$; Thais: $b=.53, p<.001$ ) and productivity (Croatians: $b=.22, p=.009$; Thais: $b=.37, p<.001$ ) than US workers. Furthermore, when examining the Croatian and Thai samples collectively against the US sample, the Croatian and Thai samples reported .50 units $(p<.001)$ higher level of well-being and .29 units $(p<.001)$ higher 
Table 5. Conditional unstandardized indirect effect of resilience on productivity and satisfaction through well-being

\begin{tabular}{|c|c|c|c|c|c|}
\hline \multirow[b]{2}{*}{ Country } & \multirow[b]{2}{*}{ Personality type } & \multirow[b]{2}{*}{ Effect } & \multicolumn{3}{|c|}{ Bootstrap $95 \% \mathrm{Cls}$} \\
\hline & & & SE & Lower bound & Upper bound \\
\hline \multicolumn{6}{|l|}{ Productivity } \\
\hline USA & Introversion & .16 & .03 & .10 & .23 \\
\hline USA & Extraversion & .19 & .03 & .13 & .26 \\
\hline Croatia & Introversion & .20 & .04 & .13 & .28 \\
\hline Croatia & Extraversion & .23 & .04 & .16 & .30 \\
\hline Thailand & Introversion & .26 & .04 & .18 & .35 \\
\hline Thailand & Extraversion & .29 & .05 & .20 & .38 \\
\hline \multicolumn{6}{|c|}{ Relational satisfaction } \\
\hline USA & Introversion & .09 & .02 & .05 & .14 \\
\hline USA & Extraversion & .10 & .02 & .06 & .14 \\
\hline Croatia & Introversion & .11 & .03 & .06 & .16 \\
\hline Croatia & Extraversion & .12 & .02 & .07 & .17 \\
\hline Thailand & Introversion & .14 & .03 & .08 & .20 \\
\hline Thailand & Extraversion & .15 & .03 & .09 & .22 \\
\hline
\end{tabular}

level of productivity than the US sample. No difference was found in the relational satisfaction score among the three countries.

Furthermore, there was a significant interaction between resilience and culture on productivity but not on relational satisfaction. The addition of the resilience-culture interaction significantly increased the variance in productivity by .007 units $\left(F(2,704)=3.17, p=.04, r^{2}\right.$ change $\left.=.007\right)$. This effect was the strongest among Croatian and Thai workers, regardless of personality type (see Table 6). As Figure 3 illustrates, the productivity level of Croatian and Thai workers increased as their perceived resilience increased. However, among US workers, productivity remained at a lower level compared to the other two countries, regardless of the level of personal resilience. Moreover, a partial moderated mediation was found for culture. Regardless of personality, the indirect effect of resilience on productivity and relational satisfaction through well-being is the stronger among Thais compared to US Americans. These results supported hypothesis $4 \mathrm{a}$ and rejected hypothesis $4 \mathrm{~b}$.

Moreover, there was a significant interaction between resilience and personality on relational satisfaction but not on productivity. The addition of the resilience and personality interaction significantly increased the variance in relational satisfaction by .005 units $(F(1,708)=4.18, p=.04$, $r^{2}$ change $\left.=.005\right)$. The addition of both personality and culture together also significantly increased the variance by .012 units $\left(F(3,708)=3.48, p=.02, r^{2}\right.$ change $\left.=.012\right)$. The effects of resilience on relational satisfaction were most prominent among introverted US workers and introverted Thai workers (see Table 6). As Figure 4 illustrates, the relational satisfaction of the US and Thai introverts increased progressively as their self-perceived resilience increased. As reported above, introverts were less satisfied with their relationships at work compared to extraverts. These moderating results suggested that, at least for the United States and Thailand, introverted workers with higher resilience fared better than introverted workers with lower resilience in terms of maintaining satisfactory workplace relationships during the COVID-19 pandemic. These results rejected hypothesis $5 \mathrm{a}$ but supported hypothesis $5 \mathrm{~b}$. 
Table 6. Unstandardized interaction effects and conditional effects of resilience by culture and personality

\begin{tabular}{|c|c|c|c|c|c|c|c|c|c|c|c|c|}
\hline \multirow[b]{2}{*}{ Variables } & \multicolumn{4}{|c|}{ Well-being } & \multicolumn{4}{|c|}{ Productivity } & \multicolumn{4}{|c|}{ Relational Satisfaction } \\
\hline & $b$ & SE & $t$ & $p$ & $b$ & $\mathrm{SE}$ & $t$ & $p$ & $b$ & SE & $t$ & $p$ \\
\hline \multicolumn{13}{|c|}{ Interaction effects between resilience and the moderators (culture and personality) } \\
\hline Resilience $\times$ CR vs. USA & .09 & .10 & .86 & .391 & .17 & .08 & 2.20 & .029 & -.15 & .08 & -1.86 & .064 \\
\hline Resilience $\times$ TH vs. USA & .23 & .11 & 2.13 & .033 & .17 & .08 & 1.98 & .048 & .02 & .09 & .25 & .802 \\
\hline Resilience $\times$ CR and TH vs. USA & .16 & .09 & 1.83 & .067 & .17 & .07 & 2.50 & .013 & -.06 & .07 & -.90 & .371 \\
\hline Resilience $\times$ TH vs. CR & .15 & .12 & 1.26 & .209 & -.00 & .09 & -.03 & .980 & .17 & .09 & 1.82 & .070 \\
\hline Resilience $\times$ Personality & .07 & .09 & .75 & .452 & -.05 & .07 & -.73 & .464 & -.15 & .07 & -2.04 & .041 \\
\hline \multicolumn{13}{|c|}{ Conditional effects of resilience by culture and personality } \\
\hline US American introverts & - & - & - & - & .01 & .06 & .23 & .818 & .20 & .07 & 2.91 & .004 \\
\hline US American extroverts & - & - & - & - & -.04 & .06 & -.57 & .569 & .05 & .07 & .763 & .446 \\
\hline Croatian introverts & - & - & - & - & .18 & .07 & 2.45 & .014 & .05 & .08 & .59 & .554 \\
\hline Croatian extroverts & - & - & - & - & .13 & .06 & 2.10 & .036 & -.10 & .07 & -1.48 & .140 \\
\hline Thai introverts & - & - & - & - & .18 & .07 & 2.43 & .016 & .22 & .08 & 2.75 & .006 \\
\hline Thai extroverts & - & - & - & - & .13 & .08 & 1.63 & .104 & .07 & .09 & .836 & .404 \\
\hline
\end{tabular}




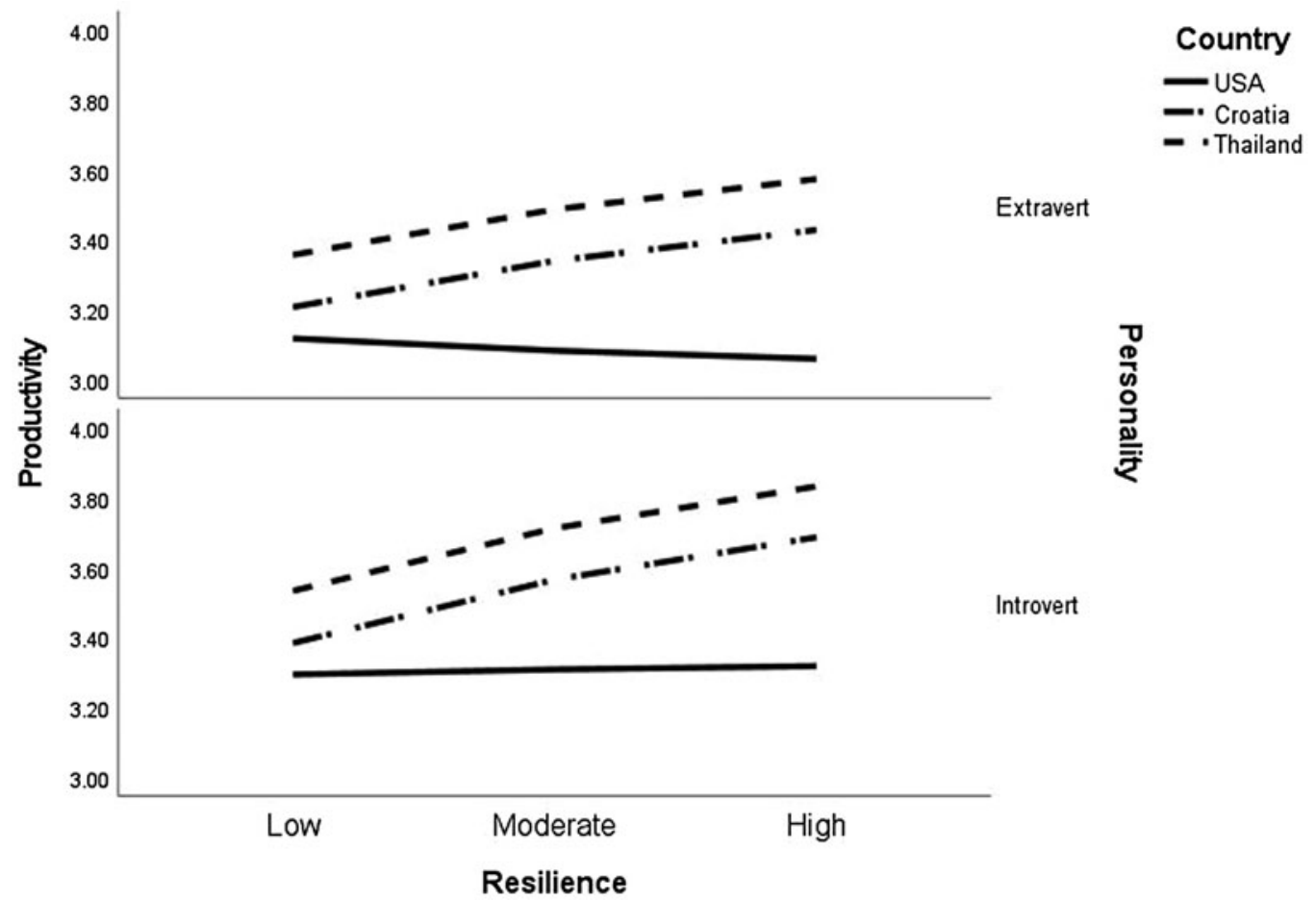

Figure 3. The conditional effect of resilience on productivity by country and personality type.

\section{Covariate effects}

The above analyses partialed out the influence of job rank, employment duration, organizational size, age, gender, and education to provide a more accurate understanding of the impact of the main predictors on the outcome variables. The results revealed that none of the organizational factors was associated with well-being. Organizational size positively predicted productivity such that those working in larger organizations (measured by the number of employees) were likely to be more productive $(b=.11, p=.001)$ compared to those in smaller organizations. On the contrary, employment duration negatively predicted both productivity $(b=-.08, p=.002)$ and relational satisfaction $(b=-.09, p=.001)$, such that those with longer tenure tended to be less productive and less satisfied with their coworkers compared to those with shorter tenure. Additionally, age was positively associated with all DVs: well-being $(b=.01, p=.001)$, productivity $(b=.007, p=.026)$, and relational satisfaction $(b=.009, p=.005)$. Finally, education positively predicted productivity such that participants with a bachelor's degree $(b=.18, p=.04)$ or above $(b=.17, p=.05)$ reported higher productivity compared to those with less than college education.

\section{Discussion}

'Resilience - for both individuals and organizations - will be an essential attribute as we move through this crisis and into the future,' writes Ignatius (2020, p. 8) in the July-August 2020 edition of Harvard Business Review, and this study supports his observation. First, across the three cultures and two personality types (extraversion vs. introversion), employee resilience was positively and strongly associated with psychological well-being which, together, predicted productivity by $32 \%$ and relational satisfaction by $11 \%$. This result suggests that during the early stages of the pandemic, those with the ability to withstand and quickly recover from this highly 


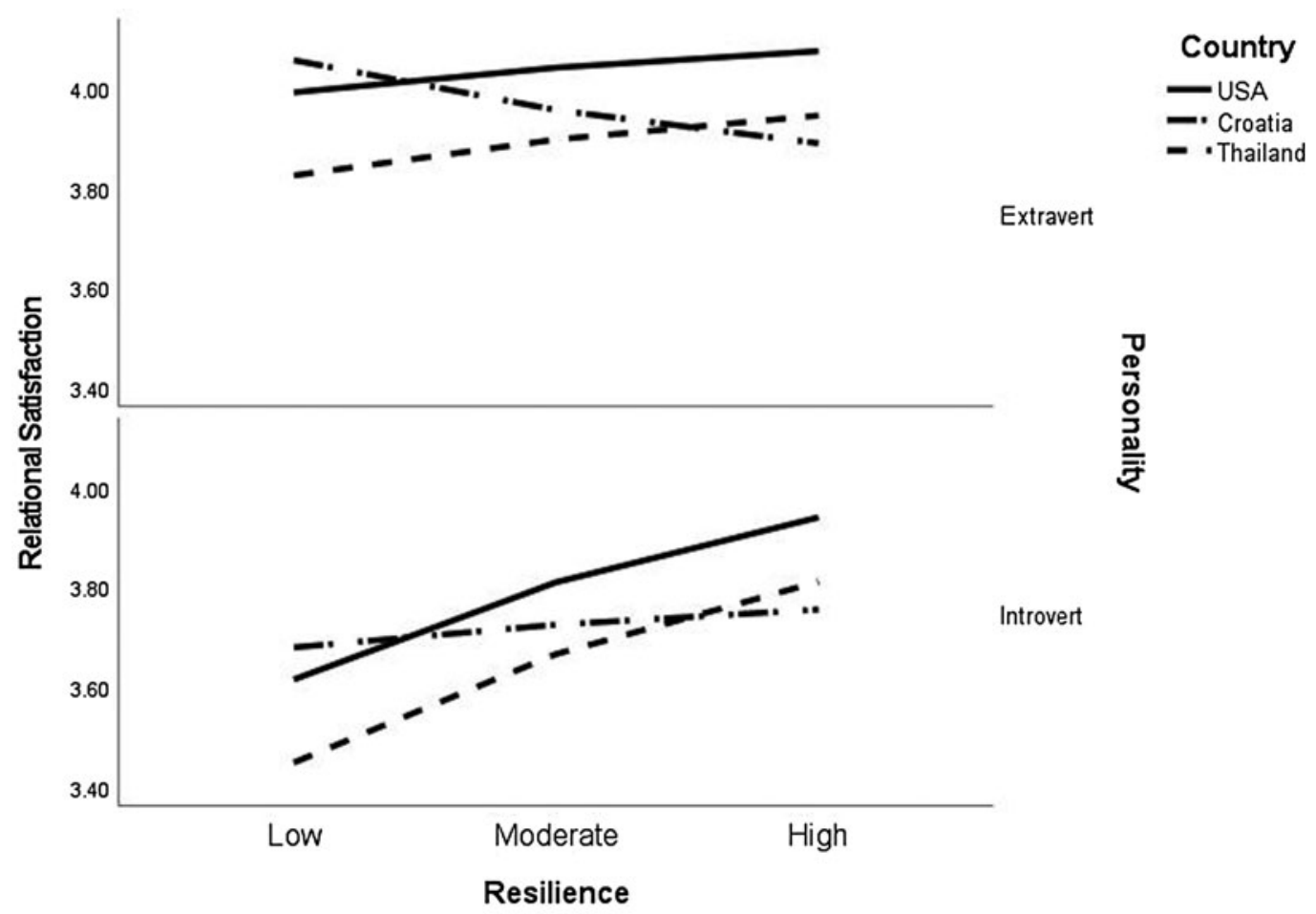

Figure 4. The conditional effect of resilience on relational satisfaction by country and personality type.

stressful and disruptive event were able to maintain a positive mental state which promoted their productivity and positive regard toward their coworkers. This finding corroborates studies that suggest resilience buffers employees from negative experiences, enabling them to remain productive and optimistic despite disruption (e.g., Hartmann et al., 2020; Kocjan, Kavčič, \& Avsec, 2021; Tugade \& Fredrickson, 2004).

Additionally, the results highlight the significant mediating effect of well-being in the relationship between resilience and productivity and relational satisfaction, respectively. This result is consistent with previous studies indicating that employee well-being was associated with higher productivity and more positive relationships at work (Donald et al., 2005; Harter, Schmidt, \& Keyes, 2003; Koopman et al., 2002; Stoll, Michaelson, \& Seaford, 2012). Interestingly, although resilience predicted an increase in relational satisfaction both directly and indirectly, resilience only indirectly predicts productivity through the intervening effect of well-being.

Another intriguing finding about well-being in our data is the insignificant relationship between personality and well-being. Although our simple regression analysis revealed a positive relationship of small effect size between extraversion and well-being, this relationship did not hold when all other variables were accounted for in the moderated mediation model. This finding indicates that the effect of personality on mental health is likely very small and dissipates when other variables are accounted for. This may explain the conflicting results on the relationship between personality traits and mental health in recent COVID-19 studies (Kocjan, Kavčič, \& Avsec, 2021; Nikčević et al., 2021; Wijngaards, Sisouw de Zilwa, \& Burger, 2020; Zacher \& Rudolph, 2021). Wijngaards, Sisouw de Zilwa, and Burger (2020) surveyed 93,125 participants across 47 countries using the original TIPI scale (Gosling, Rentfrow, \& Swann, 2003) for measuring extraversion and reported that extraversion is negatively related to depressive symptoms but with only a small effect size. When examining the moderating effect of extraversion in the 
relationship between stringent measures and depressive symptoms, they found that introverts responded more positively to stringent protective measures (e.g., social distancing and limited face-to-face interaction) and fared substantially better than extroverts. It may be the case that, in the context of COVID-19, personality has a limited impact on psychological well-being and the effect found intersects with or fades away when other factors are simultaneously examined. Our data indicated that personal resilience, age, and country were stronger predictors of psychological well-being than personality.

Nonetheless, our results suggest that employee personality does play a role in the levels of productivity and relational satisfaction during the early days of the pandemic. Unlike previous findings that extraverted employees fare better than introverts in times of stress (e.g., Bakker et al., 2006; Carver \& Connor-Smith, 2010), extraverts in this study were reportedly less productive but more satisfied with their coworkers than introverts. These results may be explained by Carver and Connor-Smith's (2010) notion that personality predicts dispositional coping better than it predicts responses to specific stressors, and an individual's response to a stressor may be strongly influenced by the event type and stressor controllability. The lower levels of productivity among extraverted participants in this study may be due to the unique characteristics of the COVID-19 pandemic and governments' protective measures (Kocjan, Kavčič, \& Avsec, 2021; Wijngaards, Sisouw de Zilwa, \& Burger, 2020). It is likely that many employees had little control over working conditions during COVID-19, and this may adversely impact those who enjoy personal interaction. For extraverts, the lack of interaction might hinder their overall energy levels and productivity whereas, for introverts, the enforced quarantine and stay-at-home orders might afford them a preferable work environment free of distractions and interruptions (Jung, 1971). Furthermore, extraverts' lower level of productivity compared to introverts was consistent with O'Neill, Hambley, Greidanus, MacDonnell, and Kline's (2009) research finding that those who are more sociable and relationship-oriented tended to report lower ratings on indices of telework performance.

On the contrary, misunderstandings and conflicts can easily occur in remote work environments (Hinds \& Mortensen, 2005). Virtual team members would need to communicate more spontaneously and informally to maintain a meaningful interpersonal connection and smooth collaboration with one another (Hinds \& Mortensen, 2005). With their general tendency to be less assertive and socially engaged (Condon \& Ruth-Sahd, 2013), introverts may feel more detached from and less satisfied with their coworkers compared to extraverts who tend to be more talkative and have a more positive outlook on relationships (Hough \& Furnham, 2003). This may explain why introverts scored higher on productivity but lower on relational satisfaction compared to extroverts in our data. Interestingly, we uncovered an interaction between personality and resilience, namely that resilience dampened the negative effects of introversion on relational satisfaction. Although extraverted workers at any resilience level reported higher levels of relational satisfaction, introverted workers with higher resilience were also likely to be satisfied with their coworkers compared to those with lower resilience. This interactive effect between resilience and personality was particularly pronounced among introverted Thai and US workers. It may be the case that introverted employees with higher resilience possessed a higher degree of flexibility and adaptability which allowed them to engage more with their coworkers (Shoss, Jiang, \& Probst, 2018), experience more positive emotions (Tugade \& Fredrickson, 2004), and maintain their relational health (Afifi, Merrill, \& Davis, 2016).

Moreover, we found both direct and moderating effects of culture on the outcome variables. Among the three countries, Thai workers significantly reported the highest level of productivity. Thai and Croatian workers also reported a significantly higher level of well-being than US workers. This pattern may be explained by the devastating impact of COVID-19 in the United States, which has likely taken a debilitating toll on its citizens' psychological well-being and productivity (Czeisler, Lane, \& Petrosky, 2020). This result may also reflect collectivism in Croatian and Thai cultures in which everyone is expected to take responsibility for fellow members of their 
organization. Also, as members of feminine cultures, Croatian and Thai employees tend to prioritize quality of life and well-being of others more than individual needs or achievements (Hofstede Insights., 2020). Perhaps, these group-oriented values helped Croatian and Thai workers sustain their psychological well-being (Brougham \& Haar, 2013; Rego \& Cunha, 2009) and productivity level (Papamarcos, Latshaw, \& Watson, 2007; Tjosvold, Law, \& Sun, 2003) in the early days of the pandemic compared to the individual-oriented values commonly present in the United States. Another intriguing finding is the moderating effect of culture in the relationship between resilience and productivity. The positive effects of resilience on productivity were strongest among Croatian and Thai workers, despite the fact that participants from the three countries in this sample were not different at their average level of personal resilience $(F(2,542.69)=1.53, p=.218)$. On the contrary, we found no differences in the relational satisfaction score among the three countries. However, the indirect effect of resilience on productivity and relational satisfaction through well-being is stronger among Thais compared to US Americans. Overall, these findings support the person-environment perspective of resilience (Herrenkohl, 2013) and SCT's assertion that an individual's behavioral outcome is determined by a dynamic interaction between personal and environmental factors (Bandura, 1988). Our results have shown that the positive effect of employee resilience is not equal across countries but increases or decreases by contextual factors, the intervening role of well-being, and the type of outcome (i.e., task or relational) being measured. Possibly, a resilient employee in an individualistic country with a higher number of COVID-19 cases may not withstand a crisis as well as a resilient employee in a collectivist country with fewer cases. Future research is needed to clarify this finding.

\section{Contributions to the resilience literature}

A recurring problem in resilience research is that employees are examined without ensuring whether they were actually exposed to adversity that would influence adaptation (Britt et al., 2016). The current study examined the participants' resilience while they were exposed to the challenges posed by COVID-19 and thus were able to test the robustness of employee resilience in relation to mental health and other organizational variables. The results of this study also supported the conceptualization of resilience as a multilevel construct (Herrenkohl, 2013) and SCT (Bandura, 1988) by demonstrating that personal resilience intersects with personality and culture to predict positive workplace outcomes. Although several studies have investigated the impact of COVID-19 on mental health (e.g., Xiong et al., 2020) and the role of resilience and/or personality traits on individual responses to the pandemic (e.g., Kocjan, Kavčič, \& Avsec, 2021; Wijngaards, Sisouw de Zilwa, \& Burger, 2020; Zacher \& Rudolph, 2021), to the best of our knowledge this is the first study that examined the interplay among employee resilience, well-being, and productivity as well as relational satisfaction across different personalities and countries during this global health crisis. Importantly, the results highlight a significant mediating role of well-being in the relationship between resilience and workplace outcomes across cultures. Notably, resilience directly predicts a relational outcome (i.e., satisfaction with coworkers) but only indirectly predicts a task outcome (i.e., productivity) through the intervening effect of well-being. This finding suggests that employees' personal capacity to swiftly bounce back and recover from the pandemic (i.e., their resilience) alone may help them maintain positive interactions with coworkers but is not sufficient to help them maintain their productivity at a desirable level. With the multitude of challenges posed by the pandemic, employees' well-being is ever more crucial for them to be able to accomplish work (Harter, Schmidt, \& Keyes, 2003; Kniffin et al., 2021; Koopman et al., 2002). Hence, organizations should provide resources and supportive policies that promote both resilience and wellbeing among their employees.

\section{Practical implications}

This study provides several pragmatic suggestions for organizational leaders during times of crisis. Our results show that, regardless of culture, well-being mediates the relationship between 
resilience and productivity, and resilience and relational satisfaction at work. Organizations should, therefore, promote resilience and well-being in the workplace culture during times of crisis. The drastic pivot toward online platforms and cloud-based workflow across many sectors during COVID-19 can create frustration, anxiety, and increased stress among employees who are struggling to meet pre-pandemic productivity levels. Recognizing this, the Centers for Disease Control and Prevention (2020) has published resources to build resilience and manage job stress during the pandemic, including communicating openly about how the pandemic is affecting work and causing stress across organizational levels, and how this stress can be resolved. Organizations should also encourage employees to practice self-care such as exercising, taking walks, or gardening which have been found to correlate with increased positive affect and play a protective role in relation to well-being during the pandemic (Lades, Laffan, Daly, \& Delaney, 2020; Plomecka et al., 2020). Management could also promote their employees' resilience by giving them the flexibility to spend quality time with their loved ones and providing adequate support for their work (e.g., information technology services or work-from-home resources) (Ojo, Fawehinmi, \& Yusliza, 2021).

Simultaneously, supervisors should consider how employees' personality types dictate varying needs, productivity levels, and overall relational satisfaction. For example, extraverted employees might benefit from frequent virtual team meetings, whereas introverts might benefit from occasional one-on-one meetings. As both extraverts and introverts ultimately have an innate need for human connection (Baumeister \& Leary, 1995) and virtual communication tools are necessary during the remote work mode, it is also important to encourage employees to use technology mindfully to stay in touch and exchange social support (Garfin, 2020). Furthermore, leaders should also explore avenues to cultivate resilience among employees that account for cultural differences. Several evidence-based intervention programs are available that aim at fostering resilience and helping employees across cultures cope positively with stressful circumstances (e.g., Joyce, Shand, Lal, Mott, Bryant, \& Harvey, 2019; Raghavan \& Sandanapitchai, 2019; Robertson, Cooper, Sarkar, \& Curran, 2015). Nevertheless, this resilience/well-being program may not always be feasible. As our results suggest, small businesses might be more adversely affected by the pandemic in terms of productivity than larger businesses, which may be due to the lack of necessary technologies or resources to fulfill job duties during this crisis (Bartik, Bertrand, Cullen, Glaeser, Luca, \& Stanton, 2020; Papadopoulos, Baltas, \& Balta, 2020). In these cases, organizations can partner with community resources to boost personal resilience among employees and ensure that they feel valued and supported (Fletcher \& Sarkar, 2013).

\section{Limitations}

This study has certain limitations that bear consideration. First, the convenience and virtual snowball sampling did not give us the control over who the participants shared the survey with, which limited our ability to compare potential differences due to recruitment channels. Also, the cross-sectional nature of the survey data, collected in the early days of the pandemic, did not allow us to test whether the effect of resilience, well-being, and personality changed over the course of several waves of the pandemic (Zacher \& Rudolph, 2021). For instance, Thailand did well in managing the spread of the virus in earlier waves (the time of our data collection) but is currently facing a sharp spike of cases.

Moreover, by considering resilience as a personal attribute, we did not directly assess why some participants were more resilient and coped more effectively than others (Britt et al., 2016). Specifically, we were unable to identify whether the resilience levels found in our participants were due to their personal resources (e.g., self-efficacy, optimism, and emotional regulation) or environmental resources (e.g., support from supervisors, friends, family, and national governments) (Hartmann et al., 2020; Ojo, Fawehinmi, \& Yusliza, 2021). 
Next, this study examined only one dimension of personality and, due to a design error as previously mentioned, measured it as a dichotomous variable (i.e., extraversion vs. introversion). Thus, this research did not capture the potentially varying degree of extraversion or introversion in the participants or other aspects of their personality (e.g., conscientiousness or openness to experience). Although our results regarding personality effects were similar to those from previous COVID studies (e.g., Kocjan, Kavčič, \& Avsec, 2021; Wijngaards, Sisouw de Zilwa, \& Burger, 2020; Zacher \& Rudolph, 2021), research has shown that people are not either an extravert or an introvert but usually score relatively low or relatively high along a continuum and most people score somewhere between the two extremes (McCrae \& Costa, 1985). Therefore, although the binary measurement of extraversion allowed us to examine this dominant personality dimension (Judge et al., 1999; Jung, 1971) in relationship with other study variables, the present findings on personality should be treated as preliminary and interpreted carefully. Finally, we did not measure individualism/collectivism at the individual level. Considering that cultural variables might be malleable to priming and other contextual factors, it is possible that the pandemic might have made people more community-minded or, at the other end, self-oriented. We should, therefore, take this into account when interpreting the results of the current study.

\section{Directions for future research}

This study of personal resilience, well-being, productivity, and workplace relationships in the early stages of a prolonged crisis provides several opportunities for future research. Considering government protective measures as well as organizational policies have changed through the several waves of the pandemic, a longitudinal study covering more recent data is needed to test our hypotheses. Using the lens of cognitive appraisal theory (Lazarus, 1991), such a study could capture how people reappraise and cope with the adversity of the pandemic as the situation evolves (Zacher \& Rudolph, 2021). Another option is to investigate the dynamic resilience processes in which employees adapt to this particular crisis, return to their previous levels of functioning, or transform into a better, new normal organizational life over time (Buzzanell \& Houston, 2018). In doing so, researchers can explore the extent to which organizational members' collective sensemaking or storytelling, via socially distanced meetings or social media channels, may shape organizational adaptation (Buzzanell, 2018). Furthermore, future studies can examine other personality dimensions and measure them as continuous variables to assess the moderating effects of personality traits more fully in the relationship between employee resilience and workplace outcomes during a crisis. Additionally, it is possible that individuals in some of the countries we studied experienced a similar health pandemic before (e.g., MERS-CoV; Bukhari et al., 2016) and may not have perceived the COVID-19 pandemic as harmful as participants from countries that did not face such a crisis. However, we did not measure participants' appraisals or earlier similar stressors that might impact their coping process. Cognitive appraisal theory argues that the relationship between stressful events and immediate or long-term outcomes can be influenced by the individuals' cognitive appraisal of the situation (e.g., whether the pandemic is threatening or to what extent one has control over it) and coping strategies (e.g., emotion-oriented or problem-oriented) (Folkman, 1984; Folkman, Lazarus, Dunkel-Schetter, DeLongis, \& Gruen, 1986). Hence, future research should explore the role of prior stressors and generalized or situational appraisals in the relationship between resilience, well-being, and organizational outcomes. Finally, it would also behoove organizational researchers to investigate the extent to which organizations that have successfully weathered past crises particularly with regard to employee and organizational resilience - were able to translate their previous success into an effective response to COVID-19 (Eaddy, 2021).

Supplementary material. The supplementary material for this article can be found at https://doi.org/10.1017/jmo.2021.58

Financial support. The authors received no financial support for the research, authorship, and/or publication of this article. 


\section{References}

Afifi, T. D., Merrill, A. F., \& Davis, S. (2016). The theory of resilience and relational load. Personal Relationships, 23(4), 663-683. https://doi.org/10.1111/pere.12159.

Aguiar-Quintana, T., Nguyen, H., Araujo-Cabrera, Y., \& Sanabria-Díaz, J. M. (2021). Do job insecurity, anxiety and depression caused by the COVID-19 pandemic influence hotel employees' self-rated task performance? The moderating role of employee resilience. International Journal of Hospitality Management, 94, 102868. https://doi.org/10.1016/j.ijhm.2021. 102868 .

Al-Zoubi, M. T. (2012). Generating benchmarking indicators for employee job satisfaction. Total Quality Management \& Business Excellence, 23(1), 27-44. https://doi.org/10.1080/14783363.2011.637780.

Andel, S. A., Shen, W., \& Arvan, M. L. (2021). Depending on your own kindness: The moderating role of self-compassion on the within-person consequences of work loneliness during the COVID-19 pandemic. Journal of Occupational Health Psychology, 26(4), 276-290. https://doi.org/10.1037/ocp0000271.

Bakker, A. B., Van der Zee, K. I., Lewig, K. A., \& Dollard, M. F. (2006). The relationship between the Big Five personality factors and burnout: A study among volunteer counsellors. The Journal of Social Psychology, 146, 31-50. https://doi.org/10. 3200/SOCP.146.1.31-50.

Bandura, A. (1988). Organisational applications of social cognitive theory. Australian Journal of Management, 13(2), 275-302. https://doi.org/10.1177/031289628801300210.

Bandura, A. (2001). Social cognitive theory and clinical psychology. In N. J. Smelser \&Oxford B. Baltes (Eds.), International encyclopedia of the social and behavioral sciences (pp. 14250-14254). Oxford: Elsevier Ltd.

Bartik, A. W., Bertrand, M., Cullen, Z., Glaeser, E. L., Luca, M., \& Stanton, C. (2020). The impact of COVID-19 on small business outcomes and expectations. Proceedings of the National Academy of Sciences, 117(30), 17656-17666. https:// doi.org/10.1073/pnas.2006991117.

Basford, T. E., \& Offermann, L. R. (2012). Beyond leadership: The impact of coworker relationships on employee motivation and intent to stay. Journal of Management \& Organization, 18(6), 807-817. https://doi.org/10.5172/jmo.2012.18.6.807.

Baumeister, R. F., \& Leary, M. R. (1995). The need to belong: Desire for interpersonal attachments as a fundamental human motivation. Psychological Bulletin, 117(3), 497-529. https://doi.org/10.1037/0033-2909.117.3.497.

Biron, M., Peretz, H., \& Turgeman-Lupo, K. (2020). Trait optimism and work from home adjustment in the COVID-19 pandemic: Considering the mediating role of situational optimism and the moderating role of cultural optimism. Sustainability, 12(22), 9773. https://doi.org/10.3390/su12229773.

Britt, T. W., Shen, W., Sinclair, R. R., Grossman, M. R., \& Klieger, D. M. (2016). How much do we really know about employee resilience? Industrial and Organizational Psychology, 9(2), 378-404. https://doi.org/10.1017/iop.2015.107.

Brougham, D., \& Haar, J. M. (2013). Collectivism, cultural identity and employee mental health: A study of New Zealand Māori. Social Indicators Research, 114, 1143-1160. https://doi.org/10.1007/s11205-012-0194-6.

Bukhari, E. E., Temsah, M. H., Aleyadhy, A. A., Alrabiaa, A. A., Alhboob, A. A., Jamal, A. A., \& Binsaeed, A. A. (2016). Middle East Respiratory syndrome coronavirus (MERS-CoV) outbreak perceptions of risk and stress evaluation in nurses. The Journal of Infection in Developing Countries, 10(08), 845-850. https://doi.org/10.3855/jidc.6925.

Bulińska-Stangrecka, H., \& Bagieńska, A. (2021). The role of employee relations in shaping job satisfaction as an element promoting positive mental health at work in the era of COVID-19. International Journal of Environmental Research and Public Health, 18(4), 1903. https://doi.org/10.3390/ijerph18041903.

Buzzanell, P. M. (2018). Organizing resilience as adaptive-transformational tensions. Journal of Applied Communication Research, 46(1), 14-18. https://doi.org/10.1080/00909882.2018.1426711.

Buzzanell, P. M., \& Houston, J. B. (2018). Communication and resilience: Multilevel applications and insights - A Journal of Applied Communication Research Forum. Journal of Applied Communication Research, 46(1), 1-4. https://doi.org/10. 1080/00909882.2017.1412086.

Cammann, C., Fichman, M., Jenkins, G. D., \& Klesh, J. R. (1983). Assessing the attitudes and perceptions of organizational members. In S. E. Seashore, E. E. Lawler, P. H. Mirvis, \& C. C. Cammann (Eds.), Assessing organizational change (pp. 71-138). New York: Wiley.

Carver, C. S., \& Connor-Smith, J. (2010). Personality and coping. Annual Review of Psychology, 61, 679-704. https://doi.org/ 10.1146/annurev.psych.093008.100352.

Centers for Disease Control and Prevention. (2020). Employees: How to cope with job stress and build resilience during the COVID-19 pandemic. Retrieved from https://www.cdc.gov/coronavirus/2019-ncov/community/mental-health-non-healthcare.html.

Cheng, S., King, D. D., \& Oswald, F. L. (2020). Understanding how resilience is measured in the organizational sciences. Human Performance, 33(2-3), 130-163. https://doi.org/10.1080/08959285.2020.1744151.

Çolak, M., \& Çetin, C. (2021). Loneliness and cyberloafing in the time of COVID-19: A psychological perspective. International Journal of Contemporary Management, 57(1), 15-27.

Condon, M., \& Ruth-Sahd, L. (2013). Responding to introverted and shy students: Best practice guidelines for educators and advisors. Open Journal of Nursing, 3, 503-515. https://doi.org/10.4236/ojn.2013.37069. 
Czeisler M. É., Lane R. I., Petrosky, E., Wiley, J. F., Christensen, A., Najai, R., Rajaratnam, S. M. W., ... (2020). Mental health, substance use, and suicidal ideation during the COVID-19 pandemic - United States, June 24-30, 2020. CDCP: Morbidity and Mortality Weekly Report, 69(32), 1049-1057. doi: https://www.cdc.gov/mmwr/volumes/69/wr/pdfs/mm6932a1-H.pdf.

Donald, I., Taylor, P., Johnson, S., Cooper, C., Cartwright, S., \& Robertson, S. (2005). Work environments, stress, and productivity: An examination using ASSET. International Journal of Stress Management, 12(4), 409-423. https://doi.org/10. 1037/1072-5245.12.4.409.

Eaddy, L. L. (2021). Unearthing the facets of crisis history in crisis communication: A conceptual framework and introduction of the crisis history salience scale. International Journal of Business Communication. https://doi.org/10.1177/ 2329488420988769.

Feng, Z., \& Savani, K. (2020). COVID-19 created a gender gap in perceived work productivity and job satisfaction: Implications for dual-career parents working from home. Gender in Management, 35(7/8), 719-736. https://doi.org/10. 1108/GM-07-2020-0202.

Fetzer, T., Witte, M., Hensel, L., Jachimowicz, J., Haushofer, J., Ivchenko, A., ... Yoeli, E. (2020). Perceptions of an insufficient government response at the onset of the COVID-19 pandemic are associated with lower mental well-being. https://doi.org/ 10.31234/osf.io/3kfmh.

Fischer, K., Reade, J. J., \& Schmal, W. B. (2021). The long shadow of an infection: COVID-19 and performance at work, Düsseldorf Institute for Competition Economics (DICE) Discussion Paper, No. 368, Heinrich Heine University, Düsseldorf. http://hdl.handle.net/10419/237290.

Fleming, J., \& Ledogar, R. J. (2008). Resilience, an evolving concept: A review of literature relevant to aboriginal research. Pimatisiwin, 6(2), 7-23.

Fletcher, D., \& Sarkar, M. (2013). Psychological resilience: A review and critique of definitions, concepts, and theory. European Psychologist, 18(1), 12-23. https://doi.org/10.1027/1016-9040/a000124.

Folkman, S. (1984). Personal control and stress and coping processes: A theoretical analysis. Journal of Personality and Social Psychology, 46(4), 839-852. https://doi.org/10.1037/0022-3514.46.4.839.

Folkman, S., Lazarus, R. S., Dunkel-Schetter, C., DeLongis, A., \& Gruen, R. J. (1986). Dynamics of a stressful encounter: Cognitive appraisal, coping, and encounter outcomes. Journal of Personality and Social Psychology, 50(5), 992-1003. https://doi.org/10.1037/0022-3514.50.5.992.

Galanti, T., Guidetti, G., Mazzei, E., Zappalà, S., \& Toscano, F. (2021). Work from home during the COVID-19 outbreak: The impact on employees' remote work productivity, engagement, and stress. Journal of Occupational and Environmental Medicine, 63(7), e426-e432. https://doi.org/10.1097/JOM.0000000000002236.

Garfin, D. R. (2020). Technology as a coping tool during the COVID-19 pandemic: Implications and recommendations. Stress and Health, 36(4), 555-559. https://doi.org/10.1002/smi.2975.

Garmezy, N. (1971). Vulnerability research and the issue of primary prevention. American Journal of Orthopsychiatry, 41(1), 101-116. https://doi.org/10.1111/j.1939-0025.1971.tb01111.x.

Gershman, J. (2020). A guide to state coronavirus reopenings and lockdowns. The Wall Street Journal. Retrieved 06/19/2020. https://www.wsj.com/articles/a-state-by-state-guide-to-coronavirus-lockdowns-11584749351.

Goldberg, L. R. (1990). An alternative 'description of personality': The Big-Five factor structure. Journal of Personality and Social Psychology, 59(6), 1216-1229. https://doi.org/10.1037/0022-3514.59.6.1216.

Gosling, S. D., Rentfrow, P. J., \& Swann, Jr. W. B. (2003). A very brief measure of the Big Five personality domains. Journal of Research in Personality, 37(6), 504-528. https://doi.org/10.1016/S0092-6566(03)00046-1.

Günaydin, H. D. (2021). Impacts of personality on job performance through COVID-19 fear and intention to quit. Psychological Reports. https://doi.org/10.1177/00332941211040433.

Hale, T., Angrist, N., Goldszmidt, R., Kira, B., Petherick, A., Phillips, T., ... Tatlow, H. (2021). A global panel database of pandemic policies (Oxford COVID-19 Government Response Tracker). Nature Human Behaviour, 5(4), 529-538. https://doi.org/10.1038/s41562-021-01079-8.

Hamill, S. K. (2003). Resilience and self-efficacy: The importance of efficacy beliefs and coping mechanisms in resilient adolescents. Colgate University Journal of the Sciences, 35(1), 115-146.

Harter, J. K., Schmidt, F. L., \& Keyes, C. L. M. (2003). Well-being in the workplace and its relationship to business outcomes: A review of the Gallup studies. In C. L. M. Keyes \& J. Haidt (Eds.), Flourishing: Positive psychology and the life well-lived (pp. 205-224). Washington, DC: American Psychological Association. https://doi.org/10.1037/10594-009.

Hartmann, S., Weiss, M., Newman, A., \& Hoegl, M. (2020). Resilience in the workplace: A multilevel review and synthesis. Applied Psychology, 69(3), 913-959. https://doi.org/10.1111/apps.12191.

Hayes, A. F. (2017). Introduction to mediation, moderation, and conditional process analysis: A regression-based approach. New York: Guilford Publications.

Herrenkohl, T. I. (2013). Person-environment interactions and the shaping of resilience. Trauma, Violence, \& Abuse, 14(3), 191-194. https://doi.org/10.1177/1524838013491035.

Hinds, P. J., \& Mortensen, M. (2005). Understanding conflict in geographically distributed teams: The moderating effects of shared identity, shared context, and spontaneous communication. Organization Science, 16(3), 290-307. https://doi.org/10. 1287/orsc.1050.0122.

Hofstede, G.. (1980). Culture's consequences: International differences in work-related values. Beverly Hills, CA: Sage. 
Hofstede Insights. (2020). Country comparison. Retrieved from https://www.hofstede-insights.com/country-comparison/.

Hough, L. M., \& Furnham, A. (2003). Use of personality variables in work settings. In W. C. Borman, D. R. Ilgen, \& R. J. Klimoski (Eds.) , Handbook of psychology: Industrial and organizational psychology (Vol. 12, pp. 131-169). Hoboken, NJ: John Wiley \& Sons Inc.

Hui, C. H., Yee, C., \& Eastman, K. L. (1995). The relationship between individualism-collectivism and job satisfaction. Applied Psychology, 44(3), 276-282. https://doi.org/10.1111/j.1464-0597.1995.tb01080.x.

Hurtz, G. M., \& Donovan, J. J. (2000). Personality and job performance: The Big Five revisited. Journal of Applied Psychology, 85(6), 869-879. https://doi.org/10.1037/0021-9010.85.6.869.

Ignatius, A. (2020, July-August). From the editor: Finding resilience. Harvard Business Review, 98(4), 8.

Joyce, S., Shand, F., Lal, T. J., Mott, B., Bryant, R. A., \& Harvey, S. B. (2019). Resilience@ work mindfulness program: Results from a cluster randomized controlled trial with first responders. Journal of Medical Internet Research, 21(2), e12894. https://doi.org/10.2196/12894.

Judge, T. A., Higgins, C. A., Thoresen, C. J., \& Barrick, M. R. (1999). The Big Five personality traits, general mental ability, and career success across the life span. Personnel Psychology, 52(3), 621-652.

Jung, C. G. (1971). Psychological types. Routledge \& Kegan Paul. (Collected Works of C. G. Jung, Vol. 6).

Kalish, Y., \& Robins, G. (2006). Psychological predispositions and network structure: The relationship between individual predispositions, structural holes and network closure. Social Networks, 28(1), 56-84. https://doi.org/10.1016/j.socnet. 2005.04.004.

Kaushik, M., \& Guleria, N. (2020). Employee relations and engagement during COVID-19. Sparkling International Journal of Multidisciplinary Research Studies, 3(2), 1-11. https://www.johnfoundation.com/journals/sparkling/sijmrsv3i2-2020/s-31/.

Khalid, S., \& Sekiguchi, T. (2019). The mediating effect of glass ceiling beliefs in the relationship between women's personality traits and their subjective career success. NTU Management Review, 29(3), 193-220.

Kniffin, K. M., Narayanan, J., Anseel, F., Antonakis, J., Ashford, S. P., Bakker, A. B., ... Vugt, M. V. (2021). COVID-19 and the workplace: Implications, issues, and insights for future research and action. American Psychologist, 76(1), 63-77. http:// dx.doi.org/10.1037/amp0000716.

Kocjan, G. Z., Kavčič, T., \& Avsec, A. (2021). Resilience matters: Explaining the association between personality and psychological functioning during the COVID-19 pandemic. International Journal of Clinical Health \& Psychology, 21(1), 1-9. https://doi.org/10.1016/j.ijchp.2020.08.002.

Koopman, C., Pelletier, K. R., Murray, J. F., Sharda, C. E., Berger, M. L., Turpin, R. S., ... Bendel, T. (2002). Stanford Presenteeism scale: Health status and employee productivity. Journal of Occupational and Environmental Medicine, 44 (1), 14-20. https://doi.org/10.1097/00043764-200201000-00004.

Labrague, L. J., \& De los Santos, J. A. A. (2020). COVID-19 anxiety among front-line nurses: Predictive role of organisational support, personal resilience and social support. Journal of Nursing Management, 28(7), 1653-1661. https://doi.org/10. 1111/jonm.13121.

Lades, L. K., Laffan, K., Daly, M., \& Delaney, L. (2020). Daily emotional well-being during the COVID-19 pandemic. British Journal of Health Psychology, 25(4), 902-911. https://doi.org/10.1111/bjhp.12450.

Lam, L., \& Lau, D. (2012). Feeling lonely at work: Investigating the consequences of unsatisfactory workplace relationships. International Journal of Human Resource Management, 23(20), 4265-4282. https://doi.org/10.1080/09585192.2012. 665070 .

Lazarus, R. S. (1991). Progress on a cognitive-motivational-relational theory of emotion. American Psychologist, 46(8), 819-834. https://psycnet.apa.org/doi/10.1037/0003-066X.46.8.819.

Lee, A. P., Teng, H. Y., \& Chen, C. Y. (2015). Workplace relationship quality and employee job outcomes in hotel firms. Journal of Human Resources in Hospitality \& Tourism, 14(4), 398-422. https://doi.org/10.1080/15332845.2015.1002068.

Lightsey, Jr. O. R. (2006). Resilience, meaning, and well-being. The Counseling Psychologist, 34(1), 96-107. https://doi.org/10. $1177 / 0011000005282369$.

Löckenhoff, C. E., Terracciano, A., Patriciu, N. S., Eaton, W. W., \& Costa, P. T. (2009). Self-reported extremely adverse life events and longitudinal changes in five-factor model personality traits in an urban sample. Journal of Traumatic Stress, 22 (1), 53-59. doi: 10.1002/jts.20385

Luthans, F., Avolio, B. J., Avey, J. B., \& Norman, S. M. (2007). Positive psychological capital: Measurement and relationship with performance and satisfaction. Personnel Psychology, 60(3), 541-572. https://doi.org/10.1111/j.1744-6570.2007.00083.x.

Mache, S., Vitzthum, K., Wanke, E., David, A., Klapp, B. F., \& Danzer, G. (2014). Exploring the impact of resilience, selfefficacy, optimism and organizational resources on work engagement. Work, 47(4), 491-500. https://doi.org/10.3233/ WOR-131617.

Martinez, A. D., Laird, M. D., Martin, J. A., \& Ferris, G. R. (2008). Job title inflation. Human Resource Management Review, 18(1), 19-27. https://doi.org/10.1016/j.hrmr.2007.12.002.

McCrae, R. R., \& Costa, P. T. (1985). Updating Norman's 'adequacy taxonomy': Intelligence and personality dimensions in natural language and in questionnaires. Journal of Personality and Social Psychology, 49(3), 710-721. https://doi.org/10. 1037/0022-3514.49.3.710 
McLarnon, M. J., \& Rothstein, M. G. (2013). Development and initial validation of the workplace resilience inventory. Journal of Personnel Psychology, 12(2), 63-73. https://doi.org/10.1027/1866-5888/a000084.

Milaković, I. K. (2021). Purchase experience during the COVID-19 pandemic and social cognitive theory: The relevance of consumer vulnerability, resilience, and adaptability for purchase satisfaction and repurchase. International Journal of Consumer Studies, 1-18. https://doi.org/10.1111/ijcs.12672.

Minbashian, A., Bright, J. E., \& Bird, K. D. (2009). Complexity in the relationships among the subdimensions of extraversion and job performance in managerial occupations. Journal of Occupational and Organizational Psychology, 82(3), 537-549. https://doi.org/10.1348/096317908X371097.

Mojtahedi, D., Dagnall, N., Denovan, A., Clough, P., Hull, S., Canning, D., .. Papageorgiou, K. A. (2021). The relationship between mental toughness, job loss, and mental health issues during the COVID-19 pandemic. Frontiers in Psychiatry, 11, 607246. https://doi.org/10.3389/fpsyt.2020.607246.

Näswall, K., Kuntz, J., Hodliffe, M., \& Malinen, S. (2013). Employee Resilience Scale (EmpRes): Technical report. Resilient Organisations Research Report, 2013/06. http://hdl.handle.net/10092/9469.

New Economics Foundation. (2014). Well-being at work: A review of the literature. White paper.

Nikčević, A. V., Marino, C., Kolubinski, D. C., Leach, D., \& Spada, M. M. (2021). Modelling the contribution of the big five personality traits, health anxiety, and COVID-19 psychological distress to generalised anxiety and depressive symptoms during the COVID-19 pandemic. Journal of Affective Disorders, 279(15), 578-584. https://doi.org/10.1016/j.jad.2020.10.053.

Ojo, A. O., Fawehinmi, O., \& Yusliza, M. Y. (2021). Examining the predictors of resilience and work engagement during the COVID-19 pandemic. Sustainability, 13(5), 2902. https://doi.org/10.3390/su13052902.

O’Neill, T. A., Hambley, L. A., Greidanus, N. S., MacDonnell, R., \& Kline, T. J. B. (2009). Predicting teleworker success: An exploration of personality, motivational, situational, and job characteristics. New Technology, Work \& Employment, 24(2), 144-162. https://doi.org/10.1111/j.1468-005X.2009.00225.x.

Papadopoulos, T., Baltas, K. N., \& Balta, M. E. (2020). The use of digital technologies by small and medium enterprises during COVID-19: Implications for theory and practice. International Journal of Information Management, 55, 102192. doi: https://doi.org/10.1016/j.ijinfomgt.2020.102192.

Papamarcos, S. D., Latshaw, C., \& Watson, G. W. (2007). Individualism-collectivism and incentive system design as predictive of productivity in a simulated cellular manufacturing environment. International Journal of Cross Cultural Management, 7 (2), 253-265. https://doi.org/10.1177/1470595807079392.

Parker, S. L., Jimmieson, N. L., Walsh, A. J., \& Loakes, J. L. (2015). Trait resilience fosters adaptive coping when control opportunities are high: Implications for the motivating potential of active work. Journal of Business and Psychology, 30, 583-604. https://doi.org/10.1007/s10869-014-9383-4.

Plomecka, M. B., Gobbi, S., Neckels, R., Radziński, P., Skórko, B., Lazerri, S., ... Jawaid, A. (2020). Mental health impact of COVID-19: A global study of risk and resilience factors. MedRxiv. https://www.medrxiv.org/content/10.1101/2020.05.05. 20092023v1.full.pdf.

Power, R. A., \& Pluess, M. (2015). Heritability estimates of the Big Five personality traits based on common genetic variants. Translational Psychiatry, 5, e604. https://doi.org/10.1038/tp.2015.96.

Prochazka, J., Scheel, T., Pirozek, P., Kratochvil, T., Civilotti, C., Bollo, M., \& Maran, D. A. (2020). Data on work-related consequences of COVID-19 pandemic for employees across Europe. Data in Brief, 32, 106174. https://doi.org/10.1016/j. dib.2020.106174.

Raghavan, S. S., \& Sandanapitchai, P. (2019). Cultural predictors of resilience in a multinational sample of trauma survivors. Frontiers in Psychology, 10, 131. https://doi.org/10.3389/fpsyg.2019.00131.

Rego, A., \& Cunha, M. P. (2009). How individualism-collectivism orientations predict happiness in a collectivistic context. Journal of Happiness Studies, 10, 19-35. https://doi.org/10.1007/s10902-007-9059-0.

Robertson, I. T., Cooper, C. L., Sarkar, M., \& Curran, T. (2015). Resilience training in the workplace from 2003 to 2014: A systematic review. Journal of Occupational and Organizational Psychology, 88(3), 533-562. https://doi.org/10.1111/joop.12120.

Rodrigues, M. F. C. C. (2019). Employees' resilience and productivity: The mediating role of well-being (Master's thesis, European University of Lisbon). Retrieved from http://hdl.handle.net/10400.26/30217.

Rossi, R., Socci, V., Talevi, D., Mensi, S., Niolu, C., Pacitti, F., ... Di Lorenzo, G. (2020). COVID-19 pandemic and lockdown measures impact on mental health among the general population in Italy. Frontiers in Psychiatry, 11, 790. https://doi.org/ $10.3389 /$ fpsyt.2020.00790.

Saakvitne, K. W., Tennen, H., \& Affleck, G. (1998). Exploring thriving in the context of clinical trauma theory: Constructivist self-development theory. Journal of Social Issues, 54, 279-299. https://doi.org/10.1111/j.1540-4560.1998.tb01219.x.

Schmidt, F. L., Hunter, J. E., \& Outerbridge, A. N. (1986). The impact of job experience and ability on job knowledge, work sample performance, and supervisory ratings of job performance. Journal of Applied Psychology, 71(1), 432-439. https:// doi.org/10.1037/0021-9010.71.3.432.

Schwarzer, R., \& Warner, L. M. (2013). Perceived self-efficacy and its relationship to resilience. In S. Prince-Embury \& D. H. Saklofske (Eds.), Resilience in children, adolescents, and adults: Translating research into practice (pp. 139-150). New York: Springer.

Shakespeare-Finch, J., Gow, K., \& Smith, S. (2005). Personality, coping and posttraumatic growth in emergency ambulance personnel. Traumatology, 11(4), 325-334. https://doi.org/10.1177/153476560501100410. 
Shoss, M. K., Jiang, L., \& Probst, T. M. (2018). Bending without breaking: A two-study examination of employee resilience in the face of job insecurity. Journal of Occupational Health Psychology, 23(1), 112-126. https://doi.org/10.1037/ocp0000060.

Smith, B. W., Dalen, J., Wiggins, K., Tooley, E., Christopher, P., \& Bernard, J. (2008). The Brief Resilience Scale: Assessing the ability to bounce back. International Journal of Behavioral Medicine, 15(3), 194-200. https://doi.org/10.1080/ 10705500802222972.

Stephens, K. K., Jahn, J. L. S., Fox, S., Charoensap-Kelly, P., Mitra, R., Sutton, J., .. Meisenbach, R. J. (2020). Collective sensemaking around COVID-19: Experiences, concerns, and agendas for our rapidly changing organizational lives. Management Communication Quarterly, 34(3), 426-457. https://doi.org/10.1177/0893318920934890.

Stevens, J. P. (2012). Applied multivariate statistics for the social sciences. New York: Routledge.

Stevis-Gridneff, M. (2020). Europe's battle-hardened nations show resilience in virus fight. The New York Times, The Coronavirus Outbreak. Retrieved 06/19/2020, https://www.nytimes.com/2020/05/10/world/europe/coronavirus-europeresilience.html.

Stoll, L., Michaelson, J., \& Seaford, C. (2012). Well-being evidence for policy: A review. London: NEF.

Taber, K. S. (2018). The use of Cronbach's alpha when developing and reporting research instruments in science education. Research in Science Education, 48(6), 1273-1296. https://doi.org/10.1007/s11165-016-9602-2.

Tjosvold, D., Law, K. S., \& Sun, H. F. (2003). Collectivistic and individualistic values: Their effects on group dynamics and productivity in China. Group Decision and Negotiation, 12, 243-263. https://doi.org/10.1023/A:1023383200180.

Topp, C. W., Østergaard, S. D., Søndergaard, S., \& Bech, P. (2015). The WHO-5 well-being index: A systematic review of the literature. Psychotherapy and Psychosomatics, 84(3), 167-176. https://doi.org/10.1159/000376585.

Toscano, F., \& Zappalà, S. (2020). Social isolation and stress as predictors of productivity perception and remote work satisfaction during the COVID-19 pandemic: The role of concern about the virus in a moderated double mediation. Sustainability, 12(23), 9804. https://doi.org/10.3390/su12239804.

Tugade, M. M., \& Fredrickson, B. L. (2004). Resilient individuals use positive emotions to bounce back from negative emotional experiences. Journal of Personality and Social Psychology, 86(2), 320. https://doi.org/10.1037/0022-3514.86.2.320.

Turpin, R. S., Ozminkowski, R. J., Sharda, C. E., Collins, J. J., Berger, M. L., Billotti, G. M., ... Nicholson, S. (2004). Reliability and validity of the Stanford Presenteeism scale. Journal of Occupational and Environmental Medicine, 46(11), $1123-1133$. https://doi.org/10.1097/01.jom.0000144999.35675.a0.

Ungar, M. (2013). Resilience, trauma, context, and culture. Trauma, Violence \& Abuse, 14(3), 255-266. https://doi.org/10. $1177 / 1524838013487805$.

Ungar, M. (2017). The differential impact of social services on young people's resilience. Child Abuse Neglect, 78, 4-12. https://doi.org/10.1016/j.chiabu.2017.09.024.

Venkataramani, V., Labianca, G. J., \& Grosser, T. (2013). Positive and negative workplace relationships, social satisfaction, and organizational attachment. Journal of Applied Psychology, 98(6), 1028-1039. https://doi.org/10.1037/a0034090.

Vinkers, C. H., van Amelsvoort, T., Bisson, J. I., Branchi, I., Cryan, J. F., Domschke, K., ... van der Wee, N. (2020). Stress resilience during the coronavirus pandemic. European Neuropsychopharmacology, 35, 12-16. https://doi.org/10.1016/j. euroneuro.2020.05.003.

Watson, D., \& Clark, L. A. (1992). On traits and temperament: General and specific factors of emotional experience and their relation to the five-factor model. Journal of Personality, 60(2), 441-476. https://doi.org/10.1111/j.1467-6494.1992.tb00980.x.

Welbourne, J. L., Gangadharan, A., \& Sariol, A. M. (2015). Ethnicity and cultural values as predictors of the occurrence and impact of experienced workplace incivility. Journal of Occupational Health Psychology, 20(2), 205-217. https://doi.org/10. 1037/a0038277.

Wijngaards, I., Sisouw de Zilwa, S. C. M., \& Burger, M. J. (2020). Extraversion moderates the relationship between the stringency of COVID-19 protective measures and depressive symptoms. Frontiers in Psychology, 11, 568907. https://doi.org/10. 3389/fpsyg.2020.568907.

Windle, G., Bennett, K. M., \& Noyes, J. (2011). A methodological review of resilience measurement scales. Health and Quality of Life Outcomes, 9(1), 1-18. doi: https://doi.org/10.1186/1477-7525-9-8.

Winefield, H. R., Gill, T. K., Taylor, A. W., \& Pilkington, R. M. (2012). Psychological well-being and psychological distress: Is it necessary to measure both? Psychology of Well-Being, Theory, Research and Practice, 2(1), 1-14. https://doi.org/10.1186/ 2211-1522-2-3.

World Health Organization (1998). Wellbeing measures in primary health care/the DEPCARE project: Report on a WHO meeting, Stockholm, Sweden 12-13 February 1998. Retrieved August 6, 2020 from https://www.euro.who.int/_data/ assets/pdf_file/0016/130750/E60246.pdf.

World Health Organization (2021). WHO Coronavirus (COVID-19) Dashboard. Retrieved 09/24/2021: https://covid19.who.int/.

Xiong, J., Lipsitz, O., Nasri, F., Lui, L. M., Gill, H., Phan, L., ... McIntyre, R. S. (2020). Impact of COVID-19 pandemic on mental health in the general population: A systematic review. Journal of Affective Disorders, 277(1), 55-64. https://doi.org/ 10.1016/j.jad.2020.08.001.

Youssef, C. M., \& Luthans, F. (2007). Positive organizational behavior in the workplace: The impact of hope, optimism, and resilience. Journal of Management, 33(5), 774-800. https://doi.org/10.1177/0149206307305562.

Zacher, H., \& Rudolph, C. W. (2021). Big Five traits as predictors of perceived stressfulness of the COVID-19 pandemic. Personality and Individual Differences, 175, 110694. https://doi.org/10.1016/j.paid.2021.110694. 
Zeidner, M., Hadar, D., Matthews, G., \& Roberts, R. D. (2013). Personal factors related to compassion fatigue in health professionals. Anxiety, Stress, and Coping, 26(6), 595-609. https://doi.org/10.1080/10615806.2013.777045.

Zopiatis, A., \& Constanti, P. (2012). Extraversion, openness and conscientiousness: The route to transformational leadership in the hotel industry. Leadership \& Organization Development Journal, 33(1), 86-104. https://doi.org/10.1108/ 01437731211193133.

Piyawan Charoensap-Kelly, Ph.D., is an Assistant Professor of Organizational Communication at Southern Methodist University. Her research interests include conflict management, crisis communication, identity management, and training and development in interpersonal, organizational, and intercultural settings. Her recent research has been published in the International Journal of Conflict Management, Management Communication Quarterly, and Business and Professional Communication Quarterly.

Pavica Sheldon, Ph.D., is a Professor \& Chair of Communication at the University of South Alabama. She is an author of three books: Social Media: Principles and Applications, Scripts and Communication for Relationships, and The Dark Side of Social Media. She has published over 50 peer-reviewed articles and book chapters.

Mary Grace Antony, Ph.D., is an Associate Faculty of Communication Studies at Edmonds College. Her research examines intercultural communication, globalization, new media discourse, and audience analysis. She has published her research in reputable journals including the Journal of International and Intercultural Communication, New Media \& Society, and Frontiers: Health Communication.

Laura Provenzani, M.A., is an Outreach Communication Specialist at the University of Alabama in Huntsville. She holds two Bachelor's degrees, Elementary Education and Art Studio and a Master's degree in Professional Communication from UAH. Her professional expertise and research interests include intercultural communication and social media usage.

Cite this article: Charoensap-Kelly P, Sheldon P, Grace Antony M, Provenzani L (2021). Resilience, well-being, and organizational outcomes of Croatian, Thai, and US workers during COVID-19. Journal of Management \& Organization 27, 1083-1111. https://doi.org/10.1017/jmo.2021.58 